\title{
NPM1/B23: A Multifunctional Chaperone in Ribosome Biogenesis and Chromatin Remodeling
}

\author{
Mikael S. Lindström \\ Department of Oncology-Pathology, Cancer Center Karolinska, CCK R8:05, Karolinska University Hospital in Solna, \\ 17176 Stockholm, Sweden \\ Correspondence should be addressed to Mikael S. Lindström, mikael.lindstrom@ki.se
}

Received 30 June 2010; Accepted 29 August 2010

Academic Editor: Nicoletta Sacchi

Copyright (๑) 2011 Mikael S. Lindström. This is an open access article distributed under the Creative Commons Attribution License, which permits unrestricted use, distribution, and reproduction in any medium, provided the original work is properly cited.

At a first glance, ribosome biogenesis and chromatin remodeling are quite different processes, but they share a common problem involving interactions between charged nucleic acids and small basic proteins that may result in unwanted intracellular aggregations. The multifunctional nuclear acidic chaperone NPM1 (B23/nucleophosmin) is active in several stages of ribosome biogenesis, chromatin remodeling, and mitosis as well as in DNA repair, replication and transcription. In addition, NPM1 plays an important role in the Myc-ARF-p53 pathway as well as in SUMO regulation. However, the relative importance of NPM1 in these processes remains unclear. Provided herein is an update on the expanding list of the diverse activities and interacting partners of NPM1. Mechanisms of NPM1 nuclear export functions of NPM1 in the nucleolus and at the mitotic spindle are discussed in relation to tumor development. It is argued that the suggested function of NPM1 as a histone chaperone could explain several, but not all, of the effects observed in cells following changes in NPM1 expression. A future challenge is to understand how NPM1 is activated, recruited, and controlled to carry out its functions.

\section{Introduction}

Ribosome biogenesis and chromatin remodeling are different processes but some parallels can be drawn. Similar to the deposition of histones onto DNA, ribosomal proteins have to bind ribosomal RNA (rRNA), and it has been assumed that both processes are prone to aggregation. With regard to size and charge, histones are reminiscent of ribosomal proteins, namely, small and basic. Histones can be divided into core histones and the $\mathrm{H} 1$ family of linker histones. Core histones $\mathrm{H} 2 \mathrm{~A}, \mathrm{H} 2 \mathrm{~B}, \mathrm{H} 3$, and $\mathrm{H} 4$ associate as $\mathrm{H} 2 \mathrm{~A} / \mathrm{H} 2 \mathrm{~B}$ dimers and $\mathrm{H} 3 / \mathrm{H} 4$ tetramers to form the histone octamer, that thus contains two $\mathrm{H} 2 \mathrm{~A} / \mathrm{H} 2 \mathrm{~B}$ dimers and a $\mathrm{H} 3 / \mathrm{H} 4$ tetramer, that the DNA is wrapped around forming a repetitive structure known as the nucleosome. Assembly of histone octamer complexes with the help of chaperones was proposed to be an ancestral feature of eukaryotes [1]. Histone chaperones are factors that bind histones and stimulate reactions involving histone transfer without being part of the final product [2].
They can be involved in histone transfer onto DNA (deposition), off DNA (eviction), from one chaperone to another, and finally histone chaperones could facilitate transfer to enzymes that use histones as substrates [2]. An emerging trend is the increasing appreciation for more active roles of histone chaperones in chromatin remodeling, for instance to increase transcription rates and facilitate replication [2, 3]. Some chaperones can store histones for a prolonged time before the actual transfer takes place and histone chaperones belonging to the nucleophosmin/nucleoplasmin family are thought to function as "storage platforms" or "sinks" [4].

Some nuclear chaperones may also play a role in ribosome biogenesis by facilitating interactions between ribosomal proteins and rRNA, a function ascribed to NPM1, although solid evidence for this function is lacking at present. Nevertheless, a fraction of NPM1 is bound to preribosomal complexes and can affect the rate of ribosome synthesis. But, NPM1 is also involved in DNA replication, recombination, transcription and repair. Whereas some of the functions of 
NPM1 are well established, others have remained less well defined. So what are the evidences surrounding these diverse but not necessarily mutually exclusive functions of NPM1? Moreover, how does the growth promoting activities of NPM1 fit with its role as tumor suppressor? Here I provide an updated overview on the functions and interacting proteins of NPM1 while addressing some of the questions above.

\section{Nucleoplasmin Family of Histone Chaperones}

NPM like proteins (e.g., NPM1-NPM3) have been found in mammals, fish, birds, flies but not in bacteria or yeast (Figure 1). There are some striking differences in expression patterns, intracellular localization and functions among the different members, but one hallmark of nucleoplasmins/nucleophosmins is a well-conserved $\mathrm{N}$ terminal oligomerisation domain [5]. Crystal structures of the oligomerisation domain from four members of the nucleoplasmin family have been resolved, namely, nucleoplasmin (Np) [6], Drosophila nucleoplasmin-like (dNLP) [7], human NPM1 [8], and Xenopus NO38/NPM1 [9]. The cores are in each case a pentamer, with minor differences between the different structures that could be important in terms of selectivity for binding partners (Figure 1(b)). NPM proteins can form a decamer structure by packing two pentamers on top of each other in a sandwich like structure and this structure is assumed to be involved in histone complex binding [9] (Figure 1(c)). The pentamers are not affected by DTT indicating that cysteine mediated disulphide bonds are not critical for the formation of pentamers, hence they are partially resistant during SDS-PAGE electrophoresis provided samples are not extensively boiled prior to loading [10-15].

Nucleoplasmin, a histone storage protein, first isolated from Xenopus laevis oocyte extracts $[16,17]$ is one of the most abundant protein in the Xenopus oocyte nucleus where it is complexed with the maternal histone pool [17, 18]. A nucleoplasmin pentamer may dimerize to form a decamer, competent for the association of five $\mathrm{H} 2 \mathrm{~A} / \mathrm{H} 2 \mathrm{~B}$ dimers or five histone octamers, and nucleoplasmin has the ability to assemble nucleosomes in vitro [6]. Nucleoplasmin binds sperm nuclear basic proteins (SNBPs), including protamines, protamine-like type and histone types [19]. Nucleoplasmin promotes decondensation and remodeling of paternal chromatin following fertilization by exchanging SNBPs for histones [20]. The chromatin remodeling activity of nucleoplasmin at fertilization has been shown to be dependent on phosphorylation status [21]. Phosphorylation of nucleoplasmin enhances the $\mathrm{H} 2 \mathrm{~A} / \mathrm{H} 2 \mathrm{~B}$ exchange activity during the decondensation of sperm chromatin and it also increases the ability of nucleoplasmin to promote nucleosome assembly in vitro, reviewed in reference [18]. Mammalian nucleoplasmin/NPM2 is expressed only in the oocyte similar to Xenopus nucleoplasmin. Knockout of Npm2 in mice have no major effect on meiosis or sperm chromatin decondensation and the $N p m 2^{-/-}$mice are viable [22]. Nevertheless, $\mathrm{Npm}^{-/-}$females have reduced fertility or infertility owing to preimplantation defects and nuclear abnormalities are evident in $\mathrm{Npm2^{-/- }}$ oocytes, including loss of heterochromatin and changes in nucleolar organization [22].

NPM3 shares many characteristics with NPM1 and NPM2 including an acidic domain and the oligomerization region, multiple potential phosphorylation sites and a nuclear localization signal [5]. NPM3 mRNA is expressed in many human tissues with high levels in pancreas and testis $[23,24]$. NPM3 protein is localized to the nucleus and nucleolus in interphase cells. Active rRNA transcription appears to be required for its nucleolar localization but on its own does not seem to bind rRNA [25]. NPM3 can bind histones [26] and affect transcription similar to NPM1, but it was shown that NPM3 lacks intrinsic histone chaperone activity in vitro [27]. $\mathrm{Npm3}^{-/-}$mice have not been reported to date but inhibition of NPM3 expression in mammalian oocytes prohibits paternal chromatin decondensation [28]. It is possible that NPM3 present in mice oocytes could provide a back up for the loss of NPM2, therefore the sperm chromatin remodeling function of NPM2 may not be critical in mammals, as suggested [5]. For an in-depth analysis of different NPM-like proteins and their evolution, I refer the reader to recent excellent articles on the topic $[5,29,30]$.

\section{NPM1 at a Glance}

3.1. Gene Structure. NPM1 (also known as nucleophosmin, NO38, numatrin or B23) is the best studied member of the NPM family and the protein is now directly linked to cancer development in humans [31]. NPM1 is highly conserved between humans, rodents, chicken and fish. Human NPM1 is mapped to chromosome $5 \mathrm{q} 35$ and composed of 12 exons. Two isoforms, besides full length wt NPM1.1, have been reported, namely, NPM1.2 and NPM1.3 (Figure 2(b)). The splice variant, NPM1.2, utilizes an alternate $3^{\prime}$-terminal exon resulting in a shorter protein containing 259 amino acids [32]. Less is known about expression and function of the recently deposited isoform NPM1.3 but this isoform lacks an internal segment in the C-terminal region, with unknown functional significance.

3.2. Protein Domain Structure. NPM1 has a distinct and unique protein domain structure (Figure 2(a)) and regions required for oligomerization, chaperone activity, nucleic acids binding, nuclear localization have been described and mapped [33-35]. There are a few more interesting features in the domain organization. The first fifteen amino acids of NPM1 is a methionine rich region but the significance of this region is not clear. It might ensure strong initiation of translation since the methionine residue codons have good Kozak sequences [36] and although not an essential part of the core this methionine rich region may also affect conformation [36]. NPM1 harbors acidic stretches known as A1, A2, and A3. These patches could play a role in charge neutralization by mimicking DNA/RNA. Whereas it is evident that the NPM1 core region alone (including acidic patch $\mathrm{A} 1$ ) can bind weakly bind histones $\mathrm{H} 3$ and $\mathrm{H} 4$ 


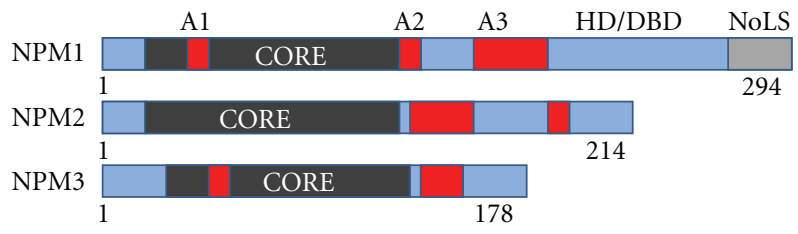

(a)

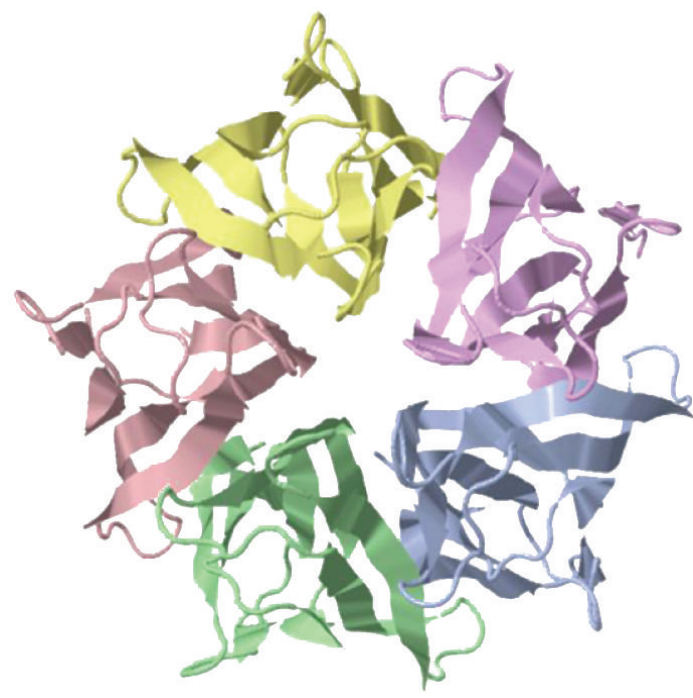

(b)

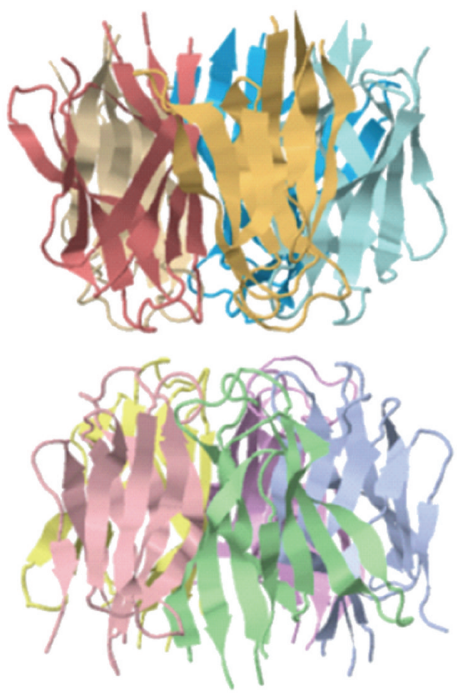

(c)

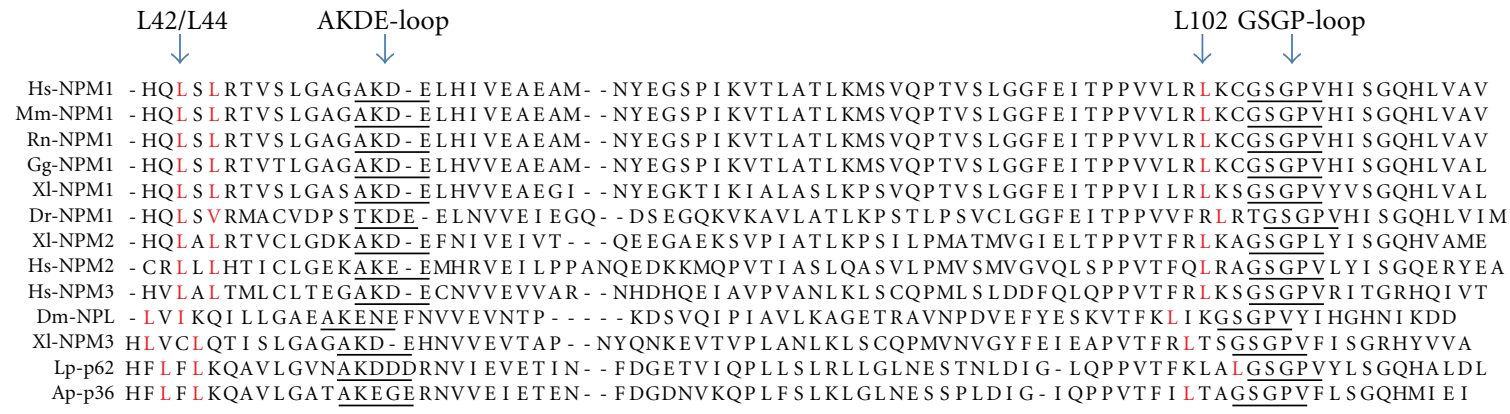

(d)

FIgURE 1: Structure of NPM1. (a) Domain representation of human NPM1, NPM2 and NPM3 proteins. Acidic patches ("A") are indicated. (HD: heterodimerization domain, DBD: DNA binding domain, NoLS: nucleolar localization motif). (b) Pentamer structure of Xenopus laevis xNPM1/NO38 (PDB ID: 1XE0) as visualized in Jalview PDB viewer. (c) Two pentamers of human NPM1 (PDB ID: 2P1B) stacked in a decameric configuration. (d) Sequence alignment of the core region from different NPM1 proteins and NPM-like proteins. Clustal W was used for alignment and further editing was done with help of Chromas alignment software. The structurally important "AKDE" and "GSGP" loops are indicated in the figure as well as the location of conserved L42 and L102 residues (reference to human NPM1). Hs: Homo sapiens; Mm: Mus musculus; Rn: Rattus norvegicus; Dr: Danio rerio; Gg: Gallus gallus; Xl: Xenopus laevis; Dm: Drosophila melanogaster; Lp: Lytechinus pictus (sea urchin); Ap: Asterina pectinifera (star fish). 


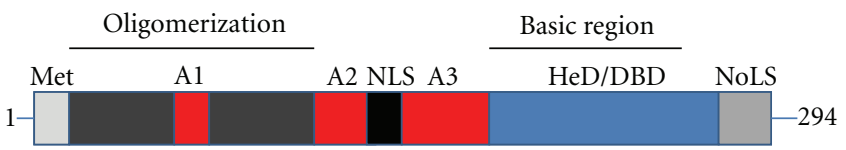

(a)

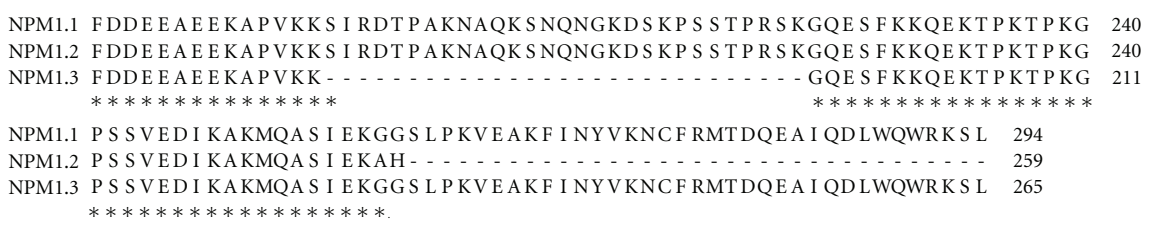

(b)

FIGURE 2: NPM1 domain organization. (a) Detailed domain representation of human NPM1 highlighting oligomerization, acidic, basic regions and where A1-A3 denotes the acidic patches (NLS: nuclear localization signal; HD: heterodimerization domain; DBD: DNA binding domain; NoLS: nucleolar localization motif). (b) Partial sequence alignment of NPM1.1 (wt) and the NPM1.2 and NPM1.3 isoforms illustrating loss of important parts of NPM1.

TABLE 1: NPM1 binding proteins.

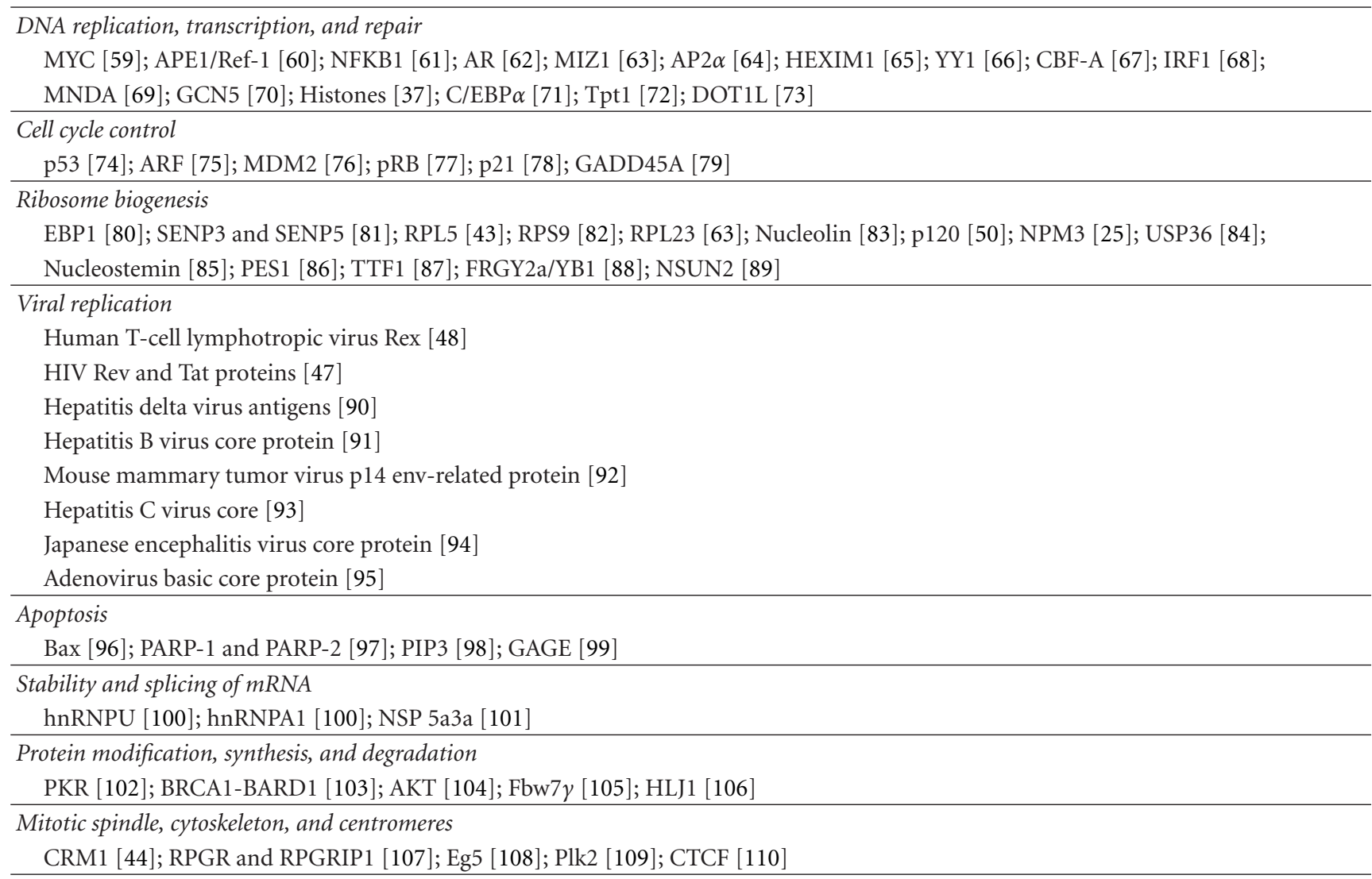

the presence of the acidic $\mathrm{A} 2$ and $\mathrm{A} 3$ patches are required for histone $\mathrm{H} 2 \mathrm{~A}$ and $\mathrm{H} 2 \mathrm{~B}$ binding [37]. The C-terminal region is unique to NPM1 and contains clusters of basic amino acids providing localized positive charge followed by a highly aromatic stretch of amino acids. This region is implicated in nucleic acid binding [34, 38], ATP binding [39], histone transfer [37], ribonuclease activity [35] and nucleolar localization $[40,41]$.
3.3. Cellular Localization. NPM1 is a nucleocytoplasmic shuttling protein [42] and motifs for nuclear import as well as nuclear export have been described. The ability of NPM1 to shuttle is critical for several of its postulated functions including nuclear export of ribosomal protein L5 [43] and control of centrosome duplication [44]. NPM1 may assist small basic proteins in their transport to the nucleolus $[45,46]$. Indeed, NPM1 was previously found to bind small 


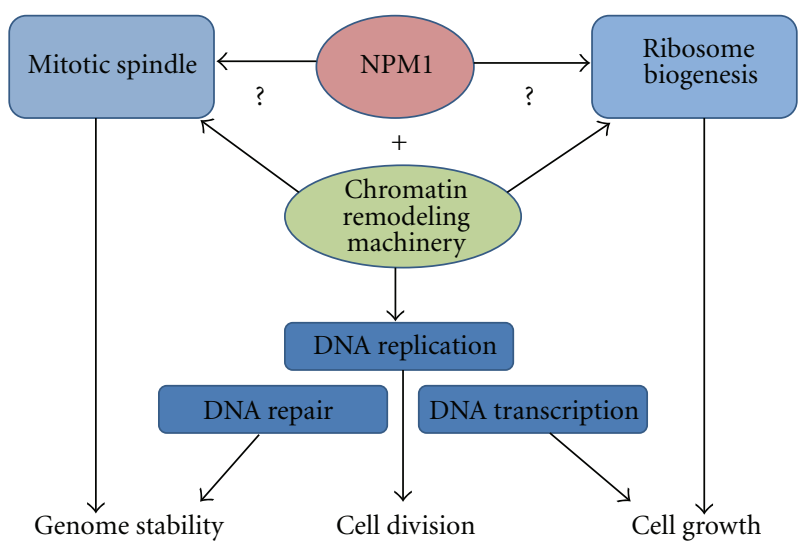

FIGURE 3: NPM1 is a multifunctional histone binding protein. NPM1 can affect DNA replication, repair and transcription by interacting with the components of chromatin such as histones and chromatin remodeling proteins. NPM1 is also required for a controlled progression through mitosis and NPM1 can promote ribosome biogenesis. These effects may arise through the ability of NPM1 to bind histones at the centromeres or in the nucleolus, respectively.

basic viral and nucleolar proteins Rev [47], Rex [48], Tat [49] and p120 [50] and promote their nucleolar localization (Table 1). NPM1 is a predominantly nucleolar protein, however, a fraction can also be detected in the nucleoplasm. NPM1 has a dynamic localization during mitosis and is observed in nucleolar remnants, at the perichromosomal layer and at the mitotic spindle pools $[51,52]$. Within the nucleolus, NPM1 is enriched in the granular component that contains maturing preribosomal particles [53]. The sequence motifs and molecular mechanisms involved in mediating nucleolar localization of NPM1 are not understood in detail but experimental evidence points out that several regions in the protein are required. Mutations in NPM1 that are predicted to disrupt both the monomer and oligomer structure markedly impair nucleolar accumulation [54]. In addition, two conserved tryptophan residues, W288 and W290, are required for NPM1 nucleolar localization, presumably by facilitating NPM1 binding to nucleic acids by providing a proper secondary structure [55]. Recently, residues K263 and K267 were shown to be functionally required for NPM1's localization to nucleoli as well as its protein stability [56, 57]. A functional nuclear localization signal is also needed [41], but some confusion in the literature exists concerning what exact motif in the central domain that is required for nuclear localization [40, 41]. NPM1.2 isoform is present in cells at low levels and is detected both in the cytoplasm and nucleoplasm further supporting the notion that the C-terminus of NPM1 contributes to nucleolar localization [58].

3.4. Protein Function In Vivo. Knockout of Npml in mice leads to unrestricted centrosome duplication, genomic instability and impaired ribosome biogenesis [111, 112]. $\mathrm{Npm}^{-/-}$mice display aberrant organogenesis, in particular the forebrain does not develop properly. The mice die between embryonic day E11.5 and E16.5 due to anemia resulting from severe defects in haematopoiesis [112]. However, mouse embryo fibroblasts lacking both $p 53$ and Npm1 are viable and can proliferate in vitro, indicating that $\mathrm{Npm} 1$ is not strictly essential for cell growth and proliferation $[111,112]$. It is also interesting that $N p m 1^{-/-}$embryos have a later timepoint of lethality compared to mouse embryos with ribosomal protein loss of function [113] suggesting an important but nonessential function of NPM1 in ribosome synthesis.

3.5. Posttranslational Modifications of NPM1. NPM1 protein is extensively modified by phosphorylation, acetylation, ubiquitylation, and SUMOylation. By studying the related protein nucleoplasmin we have learnt that phosphorylation is required for the functionality of the nucleoplasmin core domain in binding basic proteins and decondensating sperm DNA [21, 114]. From studies on nucleoplasmin we can therefore presumably learn more about NPM1 but so far, the regulation of NPM1 by phosphorylation is not well understood. NPM1 is recognized as a nucleolar phosphoprotein and several kinases, for instance casein kinase 2 (CKII) [115], polo-like kinase 2 (Plk2) [109], CDC2 [116] and cyclin E/CDK2 complex [117] can phosphorylate NPM1. Phosphorylation of NPM1 is likely to control aspects of function, localization and oligomerisation and could be related to nucleolar function and progression through mitosis [118]. Phosphorylation of NPM1 could also impinge on ribosome biogenesis by increasing NPMl's binding affinity to ribosomal components. For instance, phosphorylation by CKII enhances binding to the NLS sequences derived from the SV40 large $\mathrm{T}$ antigen and HIV Rev $[46,115]$.

A flurry of papers 2008-2009 revealed an intricate series of interactions taking place between NPM1, the ARF tumor suppressor and the SUMO-pathway. Small Ubiquitin-like Modifier (SUMO) proteins are covalently attached to other proteins to modify their function in diverse cellular processes, such as apoptosis, intracellular transport, transcriptional regulation, protein stability and DNA damage repair. The SUMO-tag is removed from its protein target by SUMOdeconjugating protease (a $\mathrm{k}$ a sentrin-specific protease or SENP). SENP3 and SENP5 are localized within nucleoli and bind NPM1 and thus NPM1 may control the SUMO pathway [119]. Knockdown of either NPM1 or nucleolar SENPs presents with similar ribosome biogenesis defects [119]. NPM1 itself is actually SUMOylated [120] although the site(s) remains a matter of debate and SUMOylation of NPM1 may affect localization and survival pathways [121]. SENP3 can remove SUMO from NPM1 [81, 122]. Interestingly, it is now realized that the ARF tumor suppressor promotes SUMOylation of several of its interacting proteins including NPM1 [123]. Mechanistically, ARF promotes the turnover of SENP3 protein [123]. NPM1 is also ubiqutinated $[54,75,103]$. USP36 is a deubiquitylating enzyme that removes ubiquitin from NPM1 leading to stabilization of NPM1 and improved nucleolar function [84] while depletion of USP36 impairs ribosome biogenesis. Interestingly, NPM1 
itself can target USP36 to nucleoli by direct binding [84]. Thus, interactions between NPM1, ubiquitin and SUMO pathways play important roles in maintaining nucleolar structure and function.

\section{NPM1: A Dual Nucleolar Histone and Ribosome Chaperone?}

NPM1 binds denatured protein substrates, a hallmark of chaperones. Indeed, one established property of NPM1 is its ability to prevent aggregation and thermal denaturation of some proteins in vitro [124]. Because NPM1 was found associated with preribosomes it was initially thought of as a ribosome chaperone or assembly factor. In support of this notion, a fraction of soluble NPM1 is associated with preribosomal particles, in particular 60S [43]. NPM1 facilitates cleavage of ribosomal RNA in vitro and acts as an endoribonuclease for the maturing rRNA transcript $[13,125]$. Knockdown of NPM1 using siRNA impairs processing of prerRNA to mature 28S [75]. Moreover, blocking NPM1 nucleocytoplasmic shuttling inhibits ribosome subunit export resulting in a decrease in cell growth rate, implicating NPM1 also in preribosome export [126]. NPM1 interact directly with a subset of ribosomal proteins including RPL5 [43], RPS9 [82], and RPL23 [63]. NPM1 forms a complex with NPM3, and NPM3 was shown to negatively regulate NPM1 during ribosome biogenesis [25]. It is noteworthy that NPM1 variants lacking the nucleic-acidbinding domain also inhibit ribosome biogenesis similar to NPM3. In summary, NPM1 promotes cell growth and proliferation by supporting several distinct stages in ribosome biogenesis.

NPM1 can assemble nucleosomes in vitro and decondense sperm DNA similar to nucleoplasmin [37, 95], and NPM1 was suggested to be a histone chaperone in the nucleolus [9]. As mentioned NPM1 associates with rDNA and depletion of NPM1 or expression of a dominant negative NPM1 mutant lacking histone chaperone activity leads to a decrease in rDNA transcription [127], although these effects have not consistently been observed by others $[111,128,129]$. Interestingly, expression of NPM3 represses the ability of NPM1 to assemble nucleosomes in vitro [27], similar to the negative regulation of NPM1 function by NPM3 seen during ribosome biogenesis. Is it possible that these regulatory functions are two sides of the same coin?

Identification of the nucleolar p14ARF/p19Arf (henceforth ARF) tumor suppressor as a major NPM1 binding partner ignited interest in the function of NPM1 in the nucleolus [75, 128, 130]. Enforced expression of ARF blocks NPM1 nucleocytoplasmic shuttling [128], increases degradation of NPM1 protein and reduces $28 \mathrm{~S}$ rRNA processing [75]. Under normal conditions, NPM1 promotes the nucleolar localization and stability of ARF, but whether NPM1 also can block ARF functions remains controversial $[131,132]$. It was argued that under normal conditions NPM1 mainly act to promote nucleolar localization of ARF [133]. Interestingly, other groups have found that ARF reduces protein synthesis by inhibiting polysome formation [129], and that ARF binds to rDNA to interfere with transcription [134]. These are interesting findings given that NPM1 binds to the rDNA gene promoter and plays a role in ribosome nuclear export. However, ARF binds to other targets than NPM1 in the nucleolus [130] and it is therefore unlikely that all the effects of ARF is funneled through NPM1. One problem in these types of studies are possible indirect effects stemming from activation of stress responses, such as p53 induced cell cycle arrest, that in some settings could complicate the interpretation of cell growth data ("the chicken and the egg problem"). A second problem could involve incomplete NPM1 knockdown in those experiments that rely on RNAi given that NPM1 is an abundant and stable protein.

\section{NPM1 Functions in DNA Replication, Transcription and Repair}

NPM1 has been implicated in the processes of DNA replication, recombination, transcription and repair, reviewed in [31]. And, as mentioned, NPM1 interacts with histones H3, $\mathrm{H} 4, \mathrm{H} 2 \mathrm{~A}$ and H2B. NPM1 may participate in chromatin remodeling related events by affecting the assembly of nucleosomes, or regulate the modification of histones through the recruitment of histone modifying enzymes. Interestingly, nucleolin (C23), a major nucleolar protein has also been implicated in DNA replication and transcription in analogy with NPM1 [135], although nucleolin and NPM1 have no structural similarity.

5.1. DNA Replication. NPM1 binds retinoblastoma protein (pRB) and synergistically stimulates DNA polymerase alpha activity in vitro and may therefore influence DNA replication processes $[77,136]$. In addition, NPM1 can also stimulate in vitro replication of adenoviral DNA [95]. Another example of a histone chaperone involved in replication is ASF1 that preferentially localizes to active DNA replication forks [137].

5.2. DNA Transcription. NPM1 has been directly implicated in gene transcription in several ways. First, NPM1 interacts with c-Myc through binding at c-Myc promoters facilitating RNA pol II driven transcription [59]. NPM1 regulates Myc protein turnover as well and may therefore directly impact on cell growth and transformation during tumor development [105]. Second, NPM1 can interact with HEXIM1, a regulator of RNA pol II transcription, to facilitate transcription [65]. Third, combination of acetylation on core histones and NPM1 itself enhances transcription rates [138]. Acetylation of NPM1 (Ac-NPM1) leads to disruption of the nucleosome and transcriptional activation. This indicates a novel and more active role of NPM1 in chromatin remodeling [138]. Ac-NPM1 is preferentially found in the nucleoplasm in association with RNA polymerase II and the increase in Ac-NPM1 seen in cancer could be of mechanistic importance [139]. On the other hand, NPM1 binds GCN5 during mitosis to inhibit GCN5 
mediated acetylation of free and mono-nucleosomal histones [70]. Fourth, NPM1 act as a corepressor or coactivator of transcription by binding to YY1, IRF1, p53, NF- $\kappa$ B and other transcription factors (Table 1). For example, it was shown that NPM1 participates in the transcriptional response to retinoic acid in myeloid cells [64]. During retinoic acid induced differentiation, NPM1 forms a complex with activating protein transcription factor $2 \alpha$, and performs a corepressor function through recruitment of histone deacetylases [64]. Fifth, and of particular interest, are the findings that NPM1 is involved in the regulation of RNA pol I transcription in the nucleolus [127], and is critical in mediating induction of rDNA transcription factor TAF(I)48 [140]. Modulation of RNA pol I transcription could be a critical activity of NPM1 because changes in rDNA transcription is an important molecular alteration in cancer cells [141]. RNA pol I activity is tightly controlled by several tumor suppressors and oncogenes such as p53 and c-Myc, respectively [142]. Because both $\mathrm{c}-\mathrm{Myc}$ and NPM1 bind to nucleolar rDNA chromatin and can stimulate RNA pol I transcription [127, 143, 144], it is likely that overexpression of NPM1 facilitates c-Myc driven rRNA synthesis, similar to how NPM1 facilitate cMyc function at RNA pol II controlled promoters. Such a mechanism could be relevant to consider when thinking about how NPM1 contributes to cell growth and oncogenic transformation. Binding of NPM1 to nucleolar chromatin requires, somewhat surprisingly, the RNA binding activity of NPM1 and indirectly the nucleolar transcription factor UBF [145]. Moreover, NPM1 facilitates nucleolar localization of the RNA polymerase I transcription termination factor (TTF-1) [87]. In summary, several lines of evidence point toward a supporting role for NPM1 in RNA pol I and II transcription.

5.3. DNA Repair. DNA strand breaks trigger activation of cellular pathways resulting in a DNA damage response and DNA repair. A DNA strand break results in global and local changes in chromatin together with activation and recruitment of several repair and signaling factors. Upon sensing DNA damage, or in the initiation of DNA repair itself, NPM1 translocates from the nucleolus to the nucleoplasm and binds chromatin [146]. In particular a pool of phosphorylated NPM1 is recruited to IR-induced DNA damage foci [147]. Inhibition of rDNA transcription or rRNA processing, in the absence of DNA damage, also often provokes rapid translocation of the otherwise predominantly nucleolar NPM1 protein to the nucleoplasm $[148,149]$ and by this change in localization NPM1 may then functionally interact with different cellular pathways. It is interesting that NPM1 mRNA and protein was found to be significantly induced following UV-induced DNA damage [150] and coupled with an increase in NPM1 expression there was enhanced RNA binding activity [151]. Enforced NPM1 expression in turn renders cells more resistant to UV-induced cell death [152]. It is conceivable that NPM1 could function as a histone chaperone under, or following, repair of DNA strand breaks. One example of a histone chaperone with a similar function already established is yeast CAF1 that mediates histone $\mathrm{H} 3-\mathrm{H} 4$ assembly during nucleotide excision repair. CAF1 is critical in chromatin assembly during double strand break repair but is not strictly needed in the repair process itself [153]. It would therefore be relevant to investigate if the NPM1 mediated prosurvival effect can be explained by a histone chaperone function active in the DNA repair process.

\section{What Is the Function of NPM1 at the Mitotic Spindle?}

The mitotic spindle includes the spindle microtubules, an array of associated proteins, and the metaphase centrosomes also present at the spindle poles. At the spindle poles, microtubules are nucleated by the centrosomes while the spindle fibers are the structures that separate the chromosomes into the daughter cells during cell division. Failure of spindle assembly can lead to spindle checkpoint activation and if not properly regulated may result in aneuploidy. $\mathrm{Npm} 1$ heterozygosity in mice led to unrestricted centrosome duplication and genomic instability $[111,112]$. Interestingly, a fraction of NPM1 protein is detected at the mitotic spindles pool during metaphase, easily detected using conventional immunofluorescence microscopy [52]. It should be pointed out that there are other nucleolar proteins at the mitotic spindles such as nucleolin and fibrillarin, meaning that NPM1 being a nucleolar protein at the spindle is not in a unique position. At the spindles, NPM1 colocalizes with NuMA (nuclear mitotic apparatus protein) [52]. The spindle pool bound form of NPM1 is modified, presumably phosphorylated, as indicated by migration shifts in immunoblots [52]. NPM1 may play a more direct role in centrosome duplication in some cells given evidence that NPM1 associates with the unduplicated centrosome in interphase and is released by $\mathrm{cdk} 2 /$ cyclin $\mathrm{E}$ mediated phosphorylation on NPM1 residue Thr199 leading to initiation of centrosome duplication [117]. Other investigators have not been able to detect NPM1 at the centrosome in interphase cells using proteomics or immunofluorescence [154], although it should be taken into consideration that the immunogenic epitopes and conformation of centrosome bound NPM1 could be different [155]. In mice, phosphorylation of Npm1 Thr198 was shown to occur throughout the cell cycle and the cell growth and proliferation rates were similar to wt NPM1. This suggests that phosphorylation of Npm1 Thr198 is not a critical event for normal cell proliferation in mice [156].

Centromeres (not to be confused with centrosomes) are the chromosomal domains that control the mitotic behavior of chromosomes. NPM1 also associates with a CENPA (Centromere protein A) containing complex [157]. CENPA encodes a histone $\mathrm{H} 3$ related histone fold domain and CENPA is a presumed component of a modified nucleosome-like structure in which it replaces histone $\mathrm{H} 3$. The finding of NPM1 in complex with CENPA implicates NPM1 also in centromere control. Recent studies confirmed NPM1 in these complexes but did not find any evidence for a major function of NPM1, although 
knockdown of NPM1 was not complete in some experiments $[158,159]$. Nevertheless, in rapidly growing HeLa cells, the depletion of NPM1 resulted in mitotic arrest due to spindle checkpoint activation and p53 induction and these cells showed signs of defects in mitotic spindle and centrosome formation [160]. Data taken together suggest a supporting histone chaperone function mediated by NPM1 involving centromeric chromatin. Interestingly, depletion of nucleolin results in growth arrest, increased apoptosis and numerous nuclear alterations, multipolar spindles together with defects in centrosome duplication [161] very similar to the inactivation of NPM1. What makes nucleolin interesting in this context is that it also functions as a histone chaperone [162]. To understand the dual function and localization of NPM1, as well as nucleolin, remains a challenge.

\section{NPM1 and Cancer}

NPM1 is clearly having both growth promoting and tumor suppressive functions. Overexpression of NPM1 enhances cell division and cell growth presumably through stimulatory effects on rDNA transcription, ribosome subunit export and DNA replication during S-phase. A transforming role for NPM1 was observed in NIH3T3 cells [68] and overexpression of NPM1 could possibly promote oncogenesis by interfering with the activation of p53 by ARF. Similar to oncogenes, such as Ras, it was found that NPM1 overexpression induces cellular senescence in human fibroblasts [74]. The level of NPM1 is generally elevated in tumor cells compared with normal cells. Increased levels of NPM1 may at least in part reflect a higher growth rate and an increased demand for ribosome biogenesis in cancer cells [163] and NPM1 is induced when B-cells, T-cells and Swiss $3 \mathrm{~T} 3$ cells are stimulated with various mitotic agents [164166]. NPM1 is overexpressed in many types of major human solid tumors including, but not limited to, tumors of the thyroid [167], brain [168], liver [169] and prostate [62]. NPM1 has been shown to be a target of oncogenic Myc and NPM1 mRNA can be directly induced by Myc through binding to the NPM1 promoter [170]. The ability of NPM1 to suppress apoptosis and to promote DNA repair may play a significant prosurvival role during tumor development. There is however no solid evidence yet demonstrating that (wt) NPM1 is acting as a bona fide proto-oncogene in vivo, when overexpressed.

Disruption of the NPM1 gene by translocation or heterozygous deletion is found in human hematopoietic malignancies [171], such as acute promyelocytic leukemia (APL), anaplastic large cell lymphoma (ALCL), and in premalignant myelodysplastic syndromes (MDS), reviewed in $[31,171]$. Interestingly, translocations occur in the NPM1 N-terminal region where it fuses to different partner genes, such as anaplastic lymphoma kinase (ALK), retinoic acid receptor $\alpha(\operatorname{RAR} \alpha)$, or myeloid leukemia factor 1 (MLF1) in ALCL, APL and MDS respectively. In these malignancies, NPM1 contributes to tumor development by activating the oncogenic potential of the fused protein partner, that is, ALK, RAR $\alpha$, or MLF1 $[172,173]$. Furthermore, loss of one allele of NPM1 is frequently observed in patients with de novo and therapy-related MDS [31]. The significance of NPM1 as a cancer gene was somewhat dubious because it was thought that the NPM1 part (of the fusion protein) was only used an essential dimerization interface. For instance, in the case of NPM1ALK, the transforming capacity correlates with an ability to form oligomers and NPM1-ALK unable to form oligomers (dimerize) is nontumorigenic [172]. This unclear role of NPM1 would change however, as it in 2005 was found that one-third of adult acute myeloid leukemia (AML) cases display aberrant cytoplasmic expression of NPM1 with mutations occurring in the exon-12 of NPM1, therefore directly implicating NPM1 as a cancer gene [174]. Analysis and clinical studies regarding NPM1c+ AML has recently been reviewed extensively and will not be covered further [175].

\section{NPM1 as a Tumor Suppressor}

NPM1 is acting as a haploinsufficient tumor suppressor in blood cells [176]. First, loss of NPM1 destabilizes the ARF protein that occurs in parallel with a failure of ARF to properly localize to nucleoli [111]. Decreased levels of ARF means increased rate of oncogenic transformation of mouse fibroblasts because ARF is critical to activate p53 in response to oncogene activation in mice $[111,177]$. The notion that NPM1 is a critical caretaker of ARF is also supported by the fact that ARF is delocalized and functionally handicapped in cells expressing AML derived oncogenic NPM1c mutants $[178,179]$. It should be mentioned that NPM1 regulates nucleolar localization of Fbw7 $\gamma$ isoform and that NPM1c has lost also this function leading to increased levels of MYC [105], given that MYC degradation requires Fbw7 $\gamma$ [180]. The intricate dynamics of the ARF-NPM1-Myc network have been reviewed elsewhere in greater detail [181]. Second, NPM1 heterozygosity results in genomic instability as shown by aneuploidy, increased centrosome numbers and DNA damage checkpoint activation that in a secondary stage enhances the rate of oncogenic transformation both in vitro and in vivo. In fact, $\mathrm{Npml}^{+/-}$mice often develop hematological malignancies following on a condition resembling myelodysplasia [112].

Disturbances in nucleolar or ribosomal function are known as nucleolar stress or ribosomal stress and are often associated with p53 tumor suppressor pathway activation [182]. Defects in the ribosome biogenesis machinery often presents with bone marrow failure and increased cancer risk. One notable syndrome is Diamond-Blackfan anemia (DBA) caused by mutations in ribosomal proteins (RPS19, RPL11, RPL5 and others) leading to defective $40 \mathrm{~S}$ or $60 S$ ribosomal subunit production with elevated risk of leukemia and osteosarcoma [183]. As mentioned earlier, inactivation of nucleolar proteins NPM1 and nucleolin also leads to mitotic spindle defects, genomic instability and accumulation of DNA damage that in turn activates $\mathrm{p} 53$. The extent of genomic instability in DBA patients is not clear. 
The point being, it is not entirely clear if reducing levels of NPM1 activates a DNA damage response, a nucleolar stress response, or both and it could be of relevance to further investigate this.

In summary, loss of one allele of NPM1 is one step closer to cancer but it is also worth noting that NPM1 has not been shown to repress genes involved in cell cycle progression, induce apoptosis in response to cell damage, or to induce cell cycle arrest following DNA damage. Therefore, NPM1 is not your "typical" tumor suppressor gene. Rather, NPM1 acts as a context dependent tumor suppressor, that is downstream of the cell cycle machinery and expression level and localization of the protein is of major importance.

\section{Mechanisms of NPM1 Nuclear Export}

Discovery of the NPM1c mutant in AML, which is a combined gain-of-function (nuclear export) and loss of function (nucleolar localization) mutant, represents a fundamental breakthrough in understanding the molecular pathogenesis of a subset of AML cases [174]. NPM1c utilizes a Crm1mediated nuclear export mechanism through a frameshift mutation resulting in the creation of a functional nuclear export signal (NES) that combined with other amino acid substitutions is working to prevent NPM1c nucleolar localization [184]. Related to the work on NPM1c, has been the parallel hunt for endogenous NES in NPM1 and two groups have found different candidate NES within the NPM1 oligomerization domain. One motif is the 42LSLRTVSL-49 sequence in hNPM1, wherein mutations L42A and L44A block NPM1 nuclear export [43]. Similarly, introducing the L102A mutation within the second NES 94-ITPPVVLRL-102 motif blocks NPM1 nuclear export [44] and interestingly, introducing the L102A mutant also prevents NPM1c shuttling. An alternative expanded model would take into consideration the structure of NPM1 core. Presumably, mutations introduced in critical loop residues within the oligomerization domain leads to a collapse and a failure to maintain the proper structure of the monomer [54]. Other mutations could impair the conformation or disrupt the hydrophobic thermostable core of NPM1 while leaving the monomeric structure relatively unaffected. Residues L102, L42 and L44 (reference to human NPM1) are all highly conserved residues in the entire nucleoplasmin family (Figure 1(d)). Conceivably, some NPM1 core mutants that have lost structural and/or functional properties will likely also affect nuclear export. In other words, NPM1 mutants with structural defects might fail to undergo export depending on the association with other cellular factors in combination with conformational changes. This model can easily be tested by further mutagenesis of conserved residues within the NPM1 core. The availability of the NPM1 core structure allows also for in silico prediction of mutations in terms of structural effects to some extent [54]. Hence, the analysis of NPM1 nuclear export should take structural effects into consideration and more remains to be discovered about NPM1 nuclear export.

\section{Targeting NPM1 in Cancer}

Under the assumption that high levels of NPM1 makes cancer cells addicted to it, knocking down NPM1 using RNAi or small molecule inhibitors could block cell growth. Inhibition of NPM1 in cancer cells but not in normal cells is therefore an attractive, but still theoretical, therapeutic approach. Retroviral HIV encoded Rev is a small basic and cytotoxic protein with a predominantly nucleolar localization, similar to ARF. A Rev derived peptide that binds to NPM1 with high affinity interferes with NPM1 function. The authors showed that NPM1's ability to transactivate a PCNA promoter construct was impaired by this Rev peptide [185]. Another peptide is CIGB-300 (P15-TAT), an anticancer peptide that can bind NPM1 and prevent CK2 driven phosphorylation leading to nucleolar breakdown and cancer cell apoptosis [186]. An interesting nonpeptide compound is avrainvillamide, an alkaloid, that targets residue C275 in human NPM1 and also induces p53 activity in cells [187].

What about small molecules that inhibit NPM1 oligomerization? The compound NSC348884 is a putative NPM1 small molecule inhibitor that disturbs NPM1 oligomer formation and induces p53 that is followed by apoptosis in cancer cells [188]. NSC348884 acts by disrupting a hydrophobic pocket required for oligomerization. In a similar study to indentify inhibitors of NPM1, Jian et al. used a SELEX to search for RNA aptamers that bind NPM1 [189]. They identified a number of RNA aptamers that bound the central region of NPM1 resulting in disturbed NPM1 oligomerization, nucleolar delocalization and increased sensitivity to apoptosis [189]. Studies in mice indicates a tumor suppressor role for NPM1 as discussed and therefore more studies are needed in order to clarify the potential usefulness of the above mentioned strategy considering then the complexity of NPM1.

\section{Other Functions of NPM1}

Undoubtedly NPM1 is a multifunctional protein that has found its way into most chapters in the cell biology text book. NPM1 was recently implicated in neural and hematopoietic stem cell fitness [190, 191], mRNA splicing and stability [192, 193], and NPM1 may even act as an alarmin in the immune system [194]. NPM1 was also found to be a nuclear PIP3 receptor, and the PIP3-NPM1 complex mediates the antiapoptotic effect of neural growth factor (NGF) through inhibition of caspase activated DNase [98]. There are several other NPM1 associated proteins than those enlisted in Table 1, but that remains less well characterized. In proteomics studies for instance, NPM1 was found associated with numerous ribosomal proteins and RNA/DNA helicases [82]. In addition, NPM1 was earlier found to associate with CDC14 (involved in centrosome organization), SNF2 (chromatin remodeling), Nup98 (nuclear pore) and CENPF (centromere protein F) [195].

There are also two interesting activities of nucleoplasmin that could be related to NPM1. First, nucleoplasmin can 
decondense chromatin in undifferentiated F9 mouse cells through epigenetic changes that involves histone modifications and release of heterochromatin proteins [196]. Through this function, nucleoplasmin enhances activation of oocyte specific genes in these mouse cell nuclei when nuclei are injected into frog eggs [196]. Second, apoptotic chromatin condensation can be regulated by nucleoplasmin [197]. Both the reprogramming and the apoptotic functions of nucleoplasmin are very interesting and it would be significant to investigate if NPM1 could have related functions.

\section{Conclusions}

As enlisted in this paper, NPM1 participates in a number of cellular processes including multiple aspects of gene expression and certain modified forms of NPM1 seem to play an active in role in RNA pol II transcription. NPM1 also interacts with a number of proteins at the mitotic spindle as well as in the nucleolus. A histone chaperone function provided by NPM1 is presumed to be of importance at each cellular location but exactly how NPM1 facilitates transcription, replication and repair remains elusive. The main function of NPM1 at a given moment could also be determined by the cell cycle stage. Hence, NPM1 may preferentially promote ribosome biogenesis in G1, facilitate DNA replication during $\mathrm{S}$-phase while supporting chromosome segregation in mitosis (Figure 3). What we now have to better understand is how NPM1 is recruited and controlled at these different "activity stations" in the cell. In this regard, the recent finding that phosphorylated NPM1 (T199-p) is specifically recruited to DNA damage sites is particularly interesting [147].

Ample amounts of data show how NPM1 participates in multiple steps in ribosome synthesis, but it is not easy to understand how NPM1 can modulate rDNA transcription, rRNA processing and export of the ribosome at the same time. Because these processes most likely are coupled, but unclear how, it will not be straightforward to dissect the functional role of NPM1 at each stage of ribosome biogenesis. Of course, a function of NPM1 on nucleolar chromatin does not exclude strictly separate later-stage functions in ribosome assembly and export given that NPM1 binds both RNA and ribosomal proteins. The same problem have surrounded nucleolin, being implicated in several ribosome biogenesis steps (rDNA transcription, rRNA processing and assembly) and associated with histone chaperone properties [162]. It now appears that one of the key roles of nucleolin is to permit transcription of rDNA genes [135]. Further studies on the role of NPM1 in ribosome biogenesis are needed to clarify its function. Especially, how NPM1 could contribute to cell growth and transformation by cooperating with oncogenes in the regulation of rDNA chromatin deserves more attention. We also need to obtain a better understanding of the general mechanisms of rDNA transcription and rRNA processing in human cells. Such efforts are in part hampered by current limitations in relevant assays to measure and monitor loading of ribosomal proteins onto RNA and the kinetics of rRNA processing.

\section{Acknowledgment}

This paper was made possible with the financial support to M. Lindström from Åke Wiberg's foundation, Karolinska Institutet and Magnus Bergvall's foundation. M. Lindström is a recipient of a fellowship from the Swedish Cancer Society (Cancerfonden). The author indebted to Professor Monica Nistér for valuable discussions and Dr Anna Eriksson for careful reading of the paper.

\section{References}

[1] L. M. Iyer, V. Anantharaman, M. Y. Wolf, and L. Aravind, "Comparative genomics of transcription factors and chromatin proteins in parasitic protists and other eukaryotes," International Journal for Parasitology, vol. 38, no. 1, pp. 1-31, 2008.

[2] L. De Koning, A. Corpet, J. E. Haber, and G. Almouzni, "Histone chaperones: an escort network regulating histone traffic," Nature Structural and Molecular Biology, vol. 14, no. 11, pp. 997-1007, 2007.

[3] A. Groth, W. Rocha, A. Verreault, and G. Almouzni, "Chromatin challenges during DNA replication and repair," Cell, vol. 128, no. 4, pp. 721-733, 2007.

[4] C. W. Akey and K. Luger, "Histone chaperones and nucleosome assembly," Current Opinion in Structural Biology, vol. 13, no. 1, pp. 6-14, 2003.

[5] L. J. Frehlick, J. M. Eirín-López, and J. Ausió, "New insights into the nucleophosmin/nucleoplasmin family of nuclear chaperones," BioEssays, vol. 29, no. 1, pp. 49-59, 2007.

[6] S. Dutta, I. V. Akey, C. Dingwall et al., "The crystal structure of nucleoplasmin-core: implications for histone binding and nucleosome assembly," Molecular Cell, vol. 8, no. 4, pp. 841853, 2001.

[7] V. M. H. Namboodiri, S. Dutta, I. V. Akey, J. F. Head, and C. W. Akey, "The crystal structure of Drosophila NLPcore provides insight into pentamer formation and histone binding," Structure, vol. 11, no. 2, pp. 175-186, 2003.

[8] H. H. Lee, H. S. Kim, J. Y. Kang et al., "Crystal structure of human nucleophosmin-core reveals plasticity of the pentamer-pentamer interface," Proteins: Structure, Function and Genetics, vol. 69, no. 3, pp. 672-678, 2007.

[9] V. M. H. Namboodiri, I. V. Akey, M. S. Schmidt-Zachmann, J. F. Head, and C. W. Akey, "The structure and function of Xenopus NO38-core, a histone chaperone in the nucleolus," Structure, vol. 12, no. 12, pp. 2149-2160, 2004.

[10] P. K. Chan, "Cross-linkage of nucleophosmin in tumor cells by nitrogen mustard," Cancer Research, vol. 49, no. 12, pp. 3271-3275, 1989.

[11] P. K. Chan and F. Y. Chan, "Nucleophosmin/B23 (NPM) oligomer is a major and stable entity in HeLa cells," Biochimica et Biophysica Acta, vol. 1262, no. 1, pp. 37-42, 1995.

[12] J. E. Herrera, J. J. Correia, A. E. Jones, and M. O. J. Olson, "Sedimentation analyses of the salt- and divalent metal ioninduced oligomerization of nucleolar protein B23," Biochemistry, vol. 35, no. 8, pp. 2668-2673, 1996.

[13] J. E. Herrera, R. Savkur, and M. O. J. Olson, "The ribonuclease activity of nucleolar protein B23," Nucleic Acids Research, vol. 23, no. 19, pp. 3974-3979, 1995. 
[14] B. Y.-M. Yung and P.-K. Chan, "Identification and characterization of a hexameric form of nucleolar phosphoprotein B23," Biochimica et Biophysica Acta, vol. 925, no. 1, pp. 74-82, 1987.

[15] B. Y.-M. Yung, E. K.-W. Hui, and P.-K. Chan, "Protein B23 (M.W./pI $=37 \mathrm{kD} / 5.1$ ) is the only major protein extracted from HeLa nucleoli with 3M urea," Life Sciences, vol. 51, no. 12, pp. 915-920, 1992.

[16] C. Dingwall, S. M. Dilworth, S. J. Black, S. E. Kearsey, L. S. Cox, and R. A. Laskey, "Nucleoplasmin cDNA sequence reveals polyglutamic acid tracts and a cluster of sequences homologous to putative nuclear localization signals," EMBO Journal, vol. 6, no. 1, pp. 69-74, 1987.

[17] C. Dingwall and R. A. Laskey, "Nucleoplasmin: the archetypal molecular chaperone," Seminars in Cell Biology, vol. 1, no. 1, pp. 11-17, 1990.

[18] A. Prado, I. Ramos, L. J. Frehlick, A. Muga, and J. Ausió, "Nucleoplasmin: a nuclear chaperone," Biochemistry and Cell Biology, vol. 82, no. 4, pp. 437-445, 2004.

[19] C. Prieto, N. Saperas, C. Arnan et al., "Nucleoplasmin interaction with protamines. Involvement of the polyglutamic tract," Biochemistry, vol. 41, no. 24, pp. 7802-7810, 2002.

[20] A. Philpott, G. H. Leno, and R. A. Laskey, "Sperm decondensation in Xenopus egg cytoplasm is mediated by nucleoplasmin," Cell, vol. 65, no. 4, pp. 569-578, 1991.

[21] M. Cotten, L. Sealy, and R. Chalkley, "Massive phosphorylation distinguishes Xenopus laevis nucleoplasmin isolated from oocytes or unfertilized eggs," Biochemistry, vol. 25, no. 18, pp. 5063-5069, 1986.

[22] K. H. Burns, M. M. Viveiros, Y. Ren et al., "Roles of NPM2 in chromatin and nucleolar organization in oocytes and embryos," Science, vol. 300, no. 5619, pp. 633-636, 2003.

[23] C. A. MacArthur and G. M. Shackleford, "Npm3: a novel, widely expressed gene encoding a protein related to the molecular chaperones nucleoplasmin and nucleophosmin," Genomics, vol. 42, no. 1, pp. 137-140, 1997.

[24] G. M. Shackleford, A. Ganguly, and C. A. MacArthur, "Cloning, expression and nuclear localization of human NPM3, a member of the nucleophosmin/nucleoplasmin family of nuclear chaperones," BMC Genomics, vol. 2, article 8, 2001.

[25] N. Huang, S. Negi, A. Szebeni, and M. O. J. Olson, "Protein NPM3 interacts with the multifunctional nucleolar protein B23/nucleophosmin and inhibits ribosome biogenesis," Journal of Biological Chemistry, vol. 280, no. 7, pp. 5496-5502, 2005.

[26] N. Motoi, K.-I. Suzuki, R. Hirota et al., "Identification and characterization of nucleoplasmin 3 as a histone-binding protein in embryonic stem cells," Development Growth and Differentiation, vol. 50, no. 5, pp. 307-320, 2008.

[27] S. S. Gadad, J. Shandilya, A. H. Kishore, and T. K. Kundu, "NPM3, a member of the nucleophosmin/nucleoplasmin family, enhances activator-dependent transcription," Biochemistry, vol. 49, no. 7, pp. 1355-1357, 2010.

[28] D. W. McLay and H. J. Clarke, "Remodelling the paternal chromatin at fertilization in mammals," Reproduction, vol. 125, no. 5, pp. 625-633, 2003.

[29] J. M. Eirín-López, L. J. Frehlick, and J. Ausió, "Long-term evolution and functional diversification in the members of the nucleophosmin/nucleoplasmin family of nuclear chaperones," Genetics, vol. 173, no. 4, pp. 1835-1850, 2006.
[30] L. J. Frehlick, J. M. Eirín-López, E. D. Jeffery, D. F. Hunt, and J. Ausió, "The characteristization of amphibian nucleoplasmins yields new insights into their role in sperm chromatin remodeling," BMC Genomics, vol. 7, article 99, 2006.

[31] S. Grisendi, C. Mecucci, B. Falini, and P. P. Pandolfi, "Nucleophosmin and cancer," Nature Reviews Cancer, vol. 6, no. 7, pp. 493-505, 2006.

[32] H. Umekawa, J.-H. Chang, J. J. Correia, D. Wang, P. T. Wingfield, and M. O. J. Olson, "Nucleolar protein B23: bacterial expression, purification, oligomerization and secondary structures of two isoforms," Cellular and Molecular Biology Research, vol. 39, no. 7, pp. 635-645, 1993.

[33] M. Okuwaki, "The structure and functions of NPM1/Nucleophsmin/B23, a multifunctional nucleolar acidic protein," Journal of Biochemistry, vol. 143, no. 4, pp. 441-448, 2008.

[34] T. S. Dumbar, G. A. Gentry, and M. O. J. Olson, "Interaction of nucleolar phosphoprotein B23 with nucleic acids," Biochemistry, vol. 28, no. 24, pp. 9495-9501, 1989.

[35] K. Hingorani, A. Szebeni, and M. O. J. Olson, "Mapping the functional domains of nucleolar protein B23," Journal of Biological Chemistry, vol. 275, no. 32, pp. 24451-24457, 2000.

[36] D. B. Ulanet, M. Torbenson, C. V. Dang, L. CasciolaRosen, and A. Rosen, "Unique conformation of cancer autoantigen B23 in hepatoma: a mechanism for specificity in the autoimmune response," Proceedings of the National Academy of Sciences of the United States of America, vol. 100, no. 21, pp. 12361-12366, 2003.

[37] M. Okuwaki, K. Matsumoto, M. Tsujimoto, and K. Nagata, "Function of nucleophosmin/B23, a nucleolar acidic protein, as a histone chaperone," FEBS Letters, vol. 506, no. 3, pp. 272276, 2001.

[38] D. Wang, A. Baumann, A. Szebeni, and M. O. J. Olson, "The nucleic acid binding activity of nucleolar protein B23.1 resides in its carboxyl-terminal end," Journal of Biological Chemistry, vol. 269, no. 49, pp. 30994-30998, 1994.

[39] J. H. Chang, J. Y. Lin, M. H. Wu, and B. Y. M. Yung, "Evidence for the ability of nucleophosmin/B23 to bind ATP," Biochemical Journal, vol. 329, no. 3, pp. 539-544, 1998.

[40] B. A. Peculis and J. G. Gall, "Localization of the nucleolar protein NO38 in amphibian oocytes," Journal of Cell Biology, vol. 116, no. 1, pp. 1-14, 1992.

[41] R. F. Zirwes, A. P. Kouzmenko, J.-M. Peters, W. W. Franke, and M. S. Schmidt-Zachmann, "Topogenesis of a nucleolar protein: determination of molecular segments directing nucleolar association," Molecular Biology of the Cell, vol. 8, no. 2, pp. 231-248, 1997.

[42] R. A. Borer, C. F. Lehner, H. M. Eppenberger, and E. A. Nigg, "Major nucleolar proteins shuttle between nucleus and cytoplasm,” Cell, vol. 56, no. 3, pp. 379-390, 1989.

[43] Y. Yu, L. B. Maggi Jr., S. N. Brady et al., "Nucleophosmin is essential for ribosomal protein L5 nuclear export," Molecular and Cellular Biology, vol. 26, no. 10, pp. 3798-3809, 2006.

[44] W. Wang, A. Budhu, M. Forgues, and X. W. Wang, "Temporal and spatial control of nucleophosmin by the Ran-Crm1 complex in centrosome duplication," Nature Cell Biology, vol. 7, no. 8, pp. 823-830, 2005.

[45] A. Szebeni, J. E. Herrera, and M. O. J. Olson, "Interaction of nucleolar protein B23 with peptides related to nuclear localization signals," Biochemistry, vol. 34, no. 25, pp. 80378042, 1995. 
[46] A. Szebeni, B. Mehrotra, A. Baumann, S. A. Adam, P. T. Wingfield, and M. O. J. Olson, "Nucleolar protein B23 stimulates nuclear import of the HIV-1 Rev protein and NLSconjugated albumin," Biochemistry, vol. 36, no. 13, pp. 39413949, 1997.

[47] C. Fankhauser, E. Izaurralde, Y. Adachi, P. Wingfield, and U. K. Laemmli, "Specific complex of human immunodeficiency virus type $1 \mathrm{Rev}$ and nucleolar B23 proteins: dissociation by the Rev response element," Molecular and Cellular Biology, vol. 11, no. 5, pp. 2567-2575, 1991.

[48] Y. Adachi, T. D. Copeland, M. Hatanaka, and S. Oroszlan, "Nucleolar targeting signal of Rex protein of human T-cell leukemia virus type I specifically binds to nucleolar shuttle protein B-23," Journal of Biological Chemistry, vol. 268, no. 19, pp. 13930-13934, 1993.

[49] Y.-P. Li, "Protein B23 is an important human factor for the nucleolar localization of the human immunodeficiency virus protein Tat," Journal of Virology, vol. 71, no. 5, pp. 4098-4102, 1997.

[50] B. C. Valdez, L. Perlaky, D. Henning, Y. Saijo, P.-K. Chan, and $\mathrm{H}$. Busch, "Identification of the nuclear and nucleolar localization signals of the protein p120. Interaction with translocation protein B23," Journal of Biological Chemistry, vol. 269, no. 38, pp. 23776-23783, 1994.

[51] M. Dundr and M. O. J. Olson, "Partially processed pre-rRNA is preserved in association with processing components in nucleolus-derived foci during mitosis," Molecular Biology of the Cell, vol. 9, no. 9, pp. 2407-2422, 1998.

[52] O. V. Zatsepina, A. Rousselet, P. K. Chan, M. O. J. Olson, E. G. Jordan, and M. Bornens, "The nucleolar phosphoprotein B23 redistributes in part to the spindle poles during mitosis," Journal of Cell Science, vol. 112, no. 4, pp. 455-466, 1999.

[53] D. L. Spector, R. L. Ochs, and H. Busch, "Silver staining, immunofluorescence, and immunoelectron microscopic localization of nucleolar phosphoproteins B23 and C23," Chromosoma, vol. 90, no. 2, pp. 139-148, 1984.

[54] T. Enomoto, M. S. Lindström, A. Jin, H. Ke, and Y. Zhang, "Essential role of the B23/NPM core domain in regulating ARF binding and B23 stability," Journal of Biological Chemistry, vol. 281, no. 27, pp. 18463-18472, 2006.

[55] Y. Nishimura, T. Ohkubo, Y. Furuichi, and H. Umekawa, "Tryptophans 286 and 288 in the C-terminal region of protein B23.1 are important for its nucleolar localization," Bioscience, Biotechnology and Biochemistry, vol. 66, no. 10, pp. 2239-2242, 2002.

[56] J. W. Choi, S. B. Lee, C. K. Kim, K.-H. Lee, S.-W. Cho, and J.-Y. Ahn, "Lysine 263 residue of NPM/B23 is essential for regulating ATP binding and B23 stability," FEBS Letters, vol. 582, no. 7, pp. 1073-1080, 2008.

[57] C. G. Grummitt, F. M. Townsley, C. M. Johnson, A. J. Warren, and M. Bycroft, "Structural consequences of nucleophosmin mutations in acute myeloid leukemia," Journal of Biological Chemistry, vol. 283, no. 34, pp. 23326-23332, 2008.

[58] D. Wang, H. Umekawa, and M. O. J. Olson, "Expression and subcellular locations of two forms of nucleolar protein B23 in rat tissues and cells," Cellular and Molecular Biology Research, vol. 39, no. 1, pp. 33-42, 1993.

[59] Z. Li, D. Boone, and S. R. Hann, "Nucleophosmin interacts directly with c-Myc and controls c-Myc-induced hyperproliferation and transformation," Proceedings of the National Academy of Sciences of the United States of America, vol. 105, no. 48, pp. 18794-18799, 2008.

[60] C. Vascotto, D. Fantini, M. Romanello et al., "APE1/Ref1 interacts with NPM1 within nucleoli and plays a role in the rRNA quality control process," Molecular and Cellular Biology, vol. 29, no. 7, pp. 1834-1854, 2009.

[61] S. K. Dhar, B. C. Lynn, C. Daosukho, and D. K. St. Clair, "Identification of nucleophosmin as an NF- $\kappa \mathrm{B}$ co-activator for the induction of the human SOD2 gene," Journal of Biological Chemistry, vol. 279, no. 27, pp. 28209-28219, 2004.

[62] L. Léotoing, L. Meunier, M. Manin et al., "Influence of nucleophosmin/B23 on DNA binding and transcriptional activity of the androgen receptor in prostate cancer cell," Oncogene, vol. 27, no. 20, pp. 2858-2867, 2008.

[63] M. Wanzel, A. C. Russ, D. Kleine-Kohlbrecher, E. Colombo, P.-G. Pelicci, and M. Eilers, "A ribosomal protein L23nucleophosmin circuit coordinates Mizl function with cell growth," Nature Cell Biology, vol. 10, no. 9, pp. 1051-1061, 2008.

[64] H. Liu, B. C.-M. Tan, K. H. Tseng et al., "Nucleophosmin acts as a novel AP $2 \alpha$-binding transcriptional corepressor during cell differentiation," EMBO Reports, vol. 8, no. 4, pp. 394400, 2007.

[65] M. Gurumurthy, C. H. Tan, R. Ng et al., "Nucleophosmin interacts with HEXIM1 and regulates RNA polymerase II transcription," Journal of Molecular Biology, vol. 378, no. 2, pp. 302-317, 2008.

[66] C. J. Inouye and E. Seto, "Relief of YY1-induced transcriptional repression by protein-protein interaction with the nucleolar phosphoprotein B23," Journal of Biological Chemistry, vol. 269, no. 9, pp. 6506-6510, 1994.

[67] A. Aranburu, M. Bennett, and T. Leanderson, "The $\kappa$ promoter penta-decamer binding protein CBF-A interacts specifically with nucleophosmin in the nucleus only," Molecular Immunology, vol. 43, no. 6, pp. 690-701, 2006.

[68] T. Kondo, N. Minamino, T. Nagamura-Inoue, M. Matsumoto, T. Taniguchi, and N. Tanaka, "Identification and characterization of nucleophosmin/B23/numatrin which binds the anti-oncogenic transcription factor IRF-1 and manifests oncogenic activity," Oncogene, vol. 15, no. 11, pp. 1275-1281, 1997.

[69] J. Xie, J. A. Briggs, S. W. Morris, M. O. J. Olson, M. C. Kinney, and R. C. Briggs, "MNDA binds NPM/B23 and the NPM-MLF1 chimera generated by the $\mathrm{t}(3 ; 5)$ associated with myelodysplastic syndrome and acute myeloid leukemia," Experimental Hematology, vol. 25, no. 11, pp. 1111-1117, 1997.

[70] Y. Zou, J. Wu, R. J. Giannone et al., "Nucleophosmin/B23 negatively regulates GCN5-dependent histone acetylation and transactivation," Journal of Biological Chemistry, vol. 283, no. 9, pp. 5728-5737, 2008.

[71] C. Müller, A. Bremer, S. Schreiber, S. Eichwald, and C. F. Calkhoven, "Nucleolar retention of a translational C/EBP $\alpha$ isoform stimulates rDNA transcription and cell size," EMBO Journal, vol. 29, no. 5, pp. 897-909, 2010.

[72] H. Johansson, D. Vizlin-Hodzic, T. Simonsson, and S. Simonsson, "Translationally controlled tumor protein interacts with nucleophosmin during mitosis in ES cells," Cell Cycle, vol. 9, no. 11, pp. 2160-2169, 2010.

[73] G. Park, Z. Gong, J. Chen, and J.-E. Kim, "Characterization of the DOT1L network: implications of diverse roles for DOT1L," Protein Journal, vol. 29, no. 3, pp. 213-223, 2010.

[74] E. Colombo, J.-C. Marine, D. Danovi, B. Falini, and P. G. Pelicci, "Nucleophosmin regulates the stability and transcriptional activity of p53," Nature Cell Biology, vol. 4, no. 7, pp. 529-533, 2002.

[75] K. Itahana, K. P. Bhat, A. Jin et al., "Tumor suppressor ARF degrades B23, a nucleolar protein involved in ribosome 
biogenesis and cell proliferation," Molecular Cell, vol. 12, no. 5, pp. 1151-1164, 2003.

[76] S. Kurki, K. Peltonen, L. Latonen et al., "Nucleolar protein NPM interacts with HDM2 and protects tumor suppressor protein p53 from HDM2-mediated degradation," Cancer Cell, vol. 5, no. 5, pp. 465-475, 2004.

[77] M. Takemura, K. Sato, M. Nishio, T. Akiyama, H. Umekawa, and S. Yoshida, "Nucleolar protein B23.1 binds to retinoblastoma protein and synergistically stimulates DNA polymerase $\alpha$ activity," Journal of Biochemistry, vol. 125, no. 5, pp. 904909, 1999.

[78] J. Xiao, Z. Zhang, G. G. Chen et al., "Nucleophosmin/B23 interacts with $\mathrm{p} 21 \mathrm{WAF} 1 / \mathrm{CIP} 1$ and contributes to its stability," Cell Cycle, vol. 8, no. 6, pp. 889-895, 2009.

[79] H. Gao, S. Jin, Y. Song et al., "B23 regulates GADD45a nuclear translocation and contributes to GADD45a-induced cell cycle G2-M arrest," Journal of Biological Chemistry, vol. 280, no. 12, pp. 10988-10996, 2005.

[80] M. Okada, S.-W. Jang, and K. Ye, "Ebp1 association with nucleophosmin/B23 is essential for regulating cell proliferation and suppressing apoptosis," Journal of Biological Chemistry, vol. 282, no. 50, pp. 36744-36754, 2007.

[81] M. Haindl, T. Harasim, D. Eick, and S. Muller, "The nucleolar SUMO-specific protease SENP3 reverses SUMO modification of nucleophosmin and is required for rRNA processing," EMBO Reports, vol. 9, no. 3, pp. 273-279, 2008.

[82] M. S. Lindström and Y. Zhang, "Ribosomal protein S9 is a novel B23/NPM-binding protein required for normal cell proliferation," Journal of Biological Chemistry, vol. 283, no. 23, pp. 15568-15576, 2008.

[83] Y.-P. Li, R. K. Busch, B. C. Valdez, and H. Busch, "C23 interacts with $\mathrm{B} 23$, a putative nucleolar-localization-signalbinding protein," European Journal of Biochemistry, vol. 237, no. 1, pp. 153-158, 1996.

[84] A. Endo, M. Matsumoto, T. Inada et al., "Nucleolar structure and function are regulated by the deubiquitylating enzyme USP36," Journal of Cell Science, vol. 122, no. 5, pp. 678-686, 2009.

[85] H. Ma and T. Pederson, "Nucleophosmin is a binding partner of nucleostemin in human osteosarcoma cells," Molecular Biology of the Cell, vol. 19, no. 7, pp. 2870-2875, 2008.

[86] J. Zhang, Y. Yang, and J. Wu, "B23 interacts with PES1 and is involved in nucleolar localization of PES1," Acta Biochimica et Biophysica Sinica, vol. 41, no. 12, pp. 991-997, 2009.

[87] F. Lessard, F. Morin, S. Ivanchuk et al., "The ARF tumor suppressor controls ribosome biogenesis by regulating the RNA polymerase I transcription factor TTF-I," Molecular Cell, vol. 38, no. 4, pp. 539-550, 2010.

[88] K. Gonda, J. Wudel, D. Nelson et al., "Requirement of the protein B23 for nucleolar disassembly induced by the FRGY2a family proteins," Journal of Biological Chemistry, vol. 281, no. 12, pp. 8153-8160, 2006.

[89] S. Sakita-Suto, A. Kanda, F. Suzuki, S. Sato, T. Takata, and M. Tatsuka, "Aurora-B regulates RNA methyltransferase NSUN2," Molecular Biology of the Cell, vol. 18, no. 3, pp. 1107-1117, 2007.

[90] W.-H. Huang, B. Y. M. Yung, W.-J. Syu, and Y.-H. W. Lee, "The nucleolar phosphoprotein B23 interacts with hepatitis delta antigens and modulates the hepatitis delta virus RNA replication," Journal of Biological Chemistry, vol. 276, no. 27, pp. 25166-25175, 2001.

[91] S. J. Lee, H. Y. Shim, A. Hsieh, J. Y. Min, and G. H. Jung, "Hepatitis B virus core interacts with the host cell nucleolar protein, nucleophosmin 1," Journal of Microbiology, vol. 47, no. 6 , pp. 746-752, 2010.

[92] H. Hoch-Marchaim, A. M. Weiss, A. Bar-Sinai, M. Fromer, K. Adermann, and J. Hochman, "The leader peptide of MMTV Env precursor localizes to the nucleoli in MMTV-derived T cell lymphomas and interacts with nucleolar protein B23," Virology, vol. 313, no. 1, pp. 22-32, 2003.

[93] R.-T. Mai, T.-S. Yeh, C.-F. Kao, S.-K. Sun, H.-H. Huang, and Y.-H. Wu Lee, "Hepatitis $\mathrm{C}$ virus core protein recruits nucleolar phosphoprotein B23 and coactivator p300 to relieve the repression effect of transcriptional factor YY1 on B23 gene expression," Oncogene, vol. 25, no. 3, pp. 448-462, 2006.

[94] Y. Tsuda, Y. Mori, T. Abe et al., "Nucleolar protein B23 interacts with Japanese encephalitis virus core protein and participates in viral replication," Microbiology and Immunology, vol. 50, no. 3, pp. 225-234, 2006.

[95] M. Okuwaki, A. Iwamatsu, M. Tsujimoto, and K. Nagata, "Identification of nucleophosmin/B23, an acidic nucleolar protein, as a stimulatory factor for in vitro replication of adenovirus DNA complexed with viral basic core proteins," Journal of Molecular Biology, vol. 311, no. 1, pp. 41-55, 2001.

[96] L. E. Kerr, J.-L. A. Birse-Archbold, D. M. Short et al., "Nucleophosmin is a novel Bax chaperone that regulates apoptotic cell death," Oncogene, vol. 26, no. 18, pp. 25542562, 2007.

[97] V. S. Meder, M. Boeglin, G. de Murcia, and V. Schreiber, "PARP-1 and PARP-2 interact with nucleophosmin/B23 and accumulate in transcriptionally active nucleoli," Journal of Cell Science, vol. 118, no. 1, pp. 211-222, 2005.

[98] J.-Y. Ahn, X. Liu, D. Cheng et al., "Nucleophosmin/B23, a nuclear $\mathrm{PI}(3,4,5) \mathrm{P} 3$ receptor, mediates the antiapoptotic actions of NGF by inhibiting CAD," Molecular Cell, vol. 18, no. 4, pp. 435-445, 2005.

[99] R. K. Kular, F. Yehiely, K. U. Kotlo, Z. M. Cilensek, R. Bedi, and L. P. Deiss, "GAGE, an antiapoptotic protein binds and modulates the expression of nucleophosmin/B23 and interferon regulatory factor 1," Journal of Interferon and Cytokine Research, vol. 29, no. 10, pp. 645-655, 2009.

[100] Z. Yao, S. Duan, D. Hou et al., "B23 acts as a nucleolar stress sensor and promotes cell survival through its dynamic interaction with hnRNPU and hnRNPA1," Oncogene, vol. 29, no. 12, pp. 1821-1834, 2010.

[101] L. D’Agostino, V. Caracciolo, and A. Giordano, "NSP 5a3a's link to nuclear-cyto proteins B23 and hnRNP-L between normal and aberrant breast cell lines," Cell Cycle, vol. 9, no. 6, pp. 1131-1142, 2010.

[102] Q. Pang, T. A. Christianson, T. Koretsky et al., "Nucleophosmin interacts with and inhibits the catalytic function of eukaryotic initiation factor 2 kinase PKR," Journal of Biological Chemistry, vol. 278, no. 43, pp. 41709-41717, 2003.

[103] K. Sato, R. Hayami, W. Wu et al., "Nucleophosmin/B23 is a candidate substrate for the BRCA1-BARD1 ubiquitin ligase," Journal of Biological Chemistry, vol. 279, no. 30, pp. 3091930922, 2004.

[104] S. B. Lee, T. L. Xuan Nguyen, J. W. Choi et al., "Nuclear Akt interacts with B23/NPM and protects it from proteolytic cleavage, enhancing cell survival," Proceedings of the National Academy of Sciences of the United States of America, vol. 105, no. 43, pp. 16584-16589, 2008.

[105] P. Bonetti, T. Davoli, C. Sironi, B. Amati, P. G. Pelicci, and E. Colombo, "Nucleophosmin and its AML-associated mutant regulate c-Myc turnover through Fbw7 $\gamma$," Journal of Cell Biology, vol. 182, no. 1, pp. 19-26, 2008. 
[106] T.-P. Chang, S.-L. Yu, S.-Y. Lin et al., “Tumor suppressor HLJ1 binds and functionally alters nucleophosmin via activating enhancer binding protein $2 \alpha$ complex formation," Cancer Research, vol. 70, no. 4, pp. 1656-1667, 2010.

[107] X. Shu, A. M. Fry, B. Tulloch et al., "RPGR ORF15 isoform co-localizes with RPGRIP1 at centrioles and basal bodies and interacts with nucleophosmin," Human Molecular Genetics, vol. 14, no. 9, pp. 1183-1197, 2005.

[108] G. Wang, X. Gao, Y. Huang et al., "Nucleophosmin/B23 inhibits Eg5-mediated microtubule depolymerization by inactivating its ATPase activity," Journal of Biological Chemistry, vol. 285, no. 25, pp. 19060-19067, 2010.

[109] A. Krause and I. Hoffmann, "Polo-like kinase 2-dependent phosphorylation of NPM/B23 on serine 4 triggers centriole duplication," PLoS One, vol. 5, artcile e9849, 2010.

[110] J. Ziatanova and P. Caiafa, "CTCF and its protein partners: divide and rule?" Journal of Cell Science, vol. 122, no. 9, pp. 1275-1284, 2009.

[111] E. Colombo, P. Bonetti, E. L. Denchi et al., "Nucleophosmin is required for DNA integrity and p19Arf protein stability," Molecular and Cellular Biology, vol. 25, no. 20, pp. 8874-8886, 2005.

[112] S. Grisendi, R. Bernardi, M. Rossi et al., "Role of nucleophosmin in embryonic development and tumorigenesis," Nature, vol. 437, no. 7055, pp. 147-153, 2005.

[113] L. Panić, S. Tamarut, M. Sticker-Jantscheff et al., "Ribosomal protein S6 gene haploinsufficiency is associated with activation of a p53-dependent checkpoint during gastrulation," Molecular and Cellular Biology, vol. 26, no. 23, pp. 8880-8891, 2006.

[114] S. Bañuelos, A. Hierro, J. M. Arizmendi, G. Montoya, A. Prado, and A. Muga, "Activation mechanism of the nuclear chaperone nucleoplasmin: role of the core domain," Journal of Molecular Biology, vol. 334, no. 3, pp. 585-593, 2003.

[115] A. Szebeni, K. Hingorani, S. Negi, and M. O. Olson, "Role of protein kinase CK2 phosphorylation in the molecular chaperone activity of nucleolar protein B23," Journal of Biological Chemistry, vol. 278, no. 11, pp. 9107-9115, 2003.

[116] M. Peter, J. Nakagawa, M. Doree, J. C. Labbe, and E. A. Nigg, "Identification of major nucleolar proteins as candidate mitotic substrates of cdc2 kinase," Cell, vol. 60, no. 5, pp. 791801, 1990.

[117] M. Okuda, H. F. Horn, P. Tarapore et al., "Nucleophos$\mathrm{min} / \mathrm{B} 23$ is a target of CDK2/cyclin E in centrosome duplication," Cell, vol. 103, no. 1, pp. 127-140, 2000.

[118] S. S. Negi and M. O. J. Olson, "Effects of interphase and mitotic phosphorylation on the mobility and location of nucleolar protein B23," Journal of Cell Science, vol. 119, no. 17, pp. 3676-3685, 2006.

[119] C. Yun, Y. Wang, D. Mukhopadhyay et al., "Nucleolar protein B23/nucleophosmin regulates the vertebrate SUMO pathway through SENP3 and SENP5 proteases," Journal of Cell Biology, vol. 183, no. 4, pp. 589-595, 2008.

[120] K. Tago, S. Chiocca, and C. J. Sherr, "Sumoylation induced by the Arf tumor suppressor: a p53-independent function," Proceedings of the National Academy of Sciences of the United States of America, vol. 102, no. 21, pp. 7689-7694, 2005.

[121] X. Liu, Z. Liu, S.-W. Jang et al., "Sumoylation of nucleophos$\mathrm{min} / \mathrm{B} 23$ regulates its subcellular localization, mediating cell proliferation and survival," Proceedings of the National Academy of Sciences of the United States of America, vol. 104, no. 23, pp. 9679-9684, 2007.

[122] T. Nishida and Y. Yamada, "SMT3IP1, a nucleolar SUMOspecific protease, deconjugates SUMO-2 from nucleolar and cytoplasmic nucleophosmin," Biochemical and Biophysical Research Communications, vol. 374, no. 2, pp. 382-387, 2008.

[123] M.-L. Kuo, W. den Besten, M. C. Thomas, and C. J. Sherr, "Arf-induced turnover of the nucleolar nucleophosminassociated SUMO-2/3 protease Senp3," Cell Cycle, vol. 7, no. 21, pp. 3378-3387, 2008.

[124] A. Szebeni and M. O. J. Olson, "Nucleolar protein B23 has molecular chaperone activities," Protein Science, vol. 8, no. 4, pp. 905-912, 1999.

[125] R. S. Savkur and M. O. J. Olson, "Preferential cleavage in preribosomal RNA by protein B23 endoribonuclease," Nucleic Acids Research, vol. 26, no. 19, pp. 4508-4515, 1998.

[126] L. B. Maggi Jr., M. Kuchenruether, D. Y. A. Dadey et al., "Nucleophosmin serves as a rate-limiting nuclear export chaperone for the mammalian ribosome," Molecular and Cellular Biology, vol. 28, no. 23, pp. 7050-7065, 2008.

[127] K. Murano, M. Okuwaki, M. Hisaoka, and K. Nagata, "Transcription regulation of the rRNA gene by a multifunctional nucleolar protein, B23/nucleophosmin, through its histone chaperone activity," Molecular and Cellular Biology, vol. 28, no. 10, pp. 3114-3126, 2008.

[128] S. N. Brady, Y. Yu, L. B. Maggi Jr., and J. D. Weber, "ARF impedes NPM/B23 shuttling in an Mdm2-sensitive tumor suppressor pathway," Molecular and Cellular Biology, vol. 24, no. 21, pp. 9327-9338, 2004.

[129] H. Rizos, H. A. McKenzie, A. L. Ayub et al., "Physical and functional interaction of the p14ARF tumor suppressor with ribosomes," Journal of Biological Chemistry, vol. 281, no. 49, pp. 38080-38088, 2006.

[130] D. Bertwistle, M. Sugimoto, and C. J. Sherr, "Physical and functional interactions of the Arf tumor suppressor protein with nucleophosmin/B23," Molecular and Cellular Biology, vol. 24, no. 3, pp. 985-996, 2004.

[131] C. Korgaonkar, J. Hagen, V. Tompkins et al., "Nucleophosmin (B23) targets ARF to nucleoli and inhibits its function," Molecular and Cellular Biology, vol. 25, no. 4, pp. 1258-1271, 2005.

[132] S. Moulin, S. Llanos, S.-H. Kim, and G. Peters, "Binding to nucleophosmin determines the localization of human and chicken ARF but not its impact on p53," Oncogene, vol. 27, no. 17, pp. 2382-2389, 2008.

[133] M. S. Lindström and Y. Zhang, "B23 and ARF: friends or foes?" Cell Biochemistry and Biophysics, vol. 46, no. 1, pp. 7990, 2006.

[134] O. Ayrault, L. Andrique, D. Fauvin, B. Eymin, S. Gazzeri, and P. Séité, "Human tumor suppressor p14ARF negatively regulates rRNA transcription and inhibits UBF1 transcription factor phosphorylation," Oncogene, vol. 25, no. 58, pp. 75777586, 2006.

[135] S. Storck, M. Shukla, S. Dimitrov, and P. Bouvet, "Functions of the histone chaperone nucleolin in diseases," Sub-cellular biochemistry, vol. 41, pp. 125-144, 2007.

[136] M. Takemura, N. Ohta, Y. Furuichi et al., "Stimulation of calf thymus DNA polymerase $\alpha$ activity by nucleolar protein B23," Biochemical and Biophysical Research Communications, vol. 199, no. 1, pp. 46-51, 1994.

[137] L. L. Schulz and J. K. Tyler, "The histone chaperone ASF1 localizes to active DNA replication forks to mediate efficient DNA replication," FASEB Journal, vol. 20, no. 3, pp. 488-490, 2006.

[138] V. Swaminathan, A. H. Kishore, K. K. Febitha, and T. K. Kundu, "Human histone chaperone nucleophosmin enhances acetylation-dependent chromatin transcription," 
Molecular and Cellular Biology, vol. 25, no. 17, pp. 7534-7545, 2005.

[139] J. Shandilya, V. Swaminathan, S. S. Gadad, R. Choudhari, G. S. Kodaganur, and T. K. Kundu, "Acetylated NPM1 localizes in the nucleoplasm and regulates transcriptional activation of genes implicated in oral cancer manifestation," Molecular and Cellular Biology, vol. 29, no. 18, pp. 5115-5127, 2009.

[140] D. T. Bergstralh, B. J. Conti, C. B. Moore, W. J. Brickey, D. J. Taxman, and J. P.-Y. Ting, "Global functional analysis of nucleophosmin in Taxol response, cancer, chromatin regulation, and ribosomal DNA transcription," Experimental Cell Research, vol. 313, no. 1, pp. 65-76, 2007.

[141] D. Drygin, W. G. Rice, and I. Grummt, "The RNA polymerase i transcription machinery: an emerging target for the treatment of cancer," Annual Review of Pharmacology and Toxicology, vol. 50, pp. 131-156, 2010.

[142] R. J. White, "RNA polymerases I and III, non-coding RNAs and cancer," Trends in Genetics, vol. 24, no. 12, pp. 622-629, 2008.

[143] A. Arabi, S. Wu, K. Ridderstråle et al., "c-Myc associates with ribosomal DNA and activates RNA polymerase I transcription," Nature Cell Biology, vol. 7, no. 3, pp. 303-310, 2005.

[144] C. Grandori, N. Gomez-Roman, Z. A. Felton-Edkins et al., "c-Myc binds to human ribosomal DNA and stimulates transcription of rRNA genes by RNA polymerase I," Nature Cell Biology, vol. 7, no. 3, pp. 311-318, 2005.

[145] M. Hisaoka, S. Ueshima, K. Murano, K. Nagata, and M. Okuwaki, "Regulation of nucleolar chromatin by B23/nucleophosmin jointly depends upon its RNA binding activity and transcription factor UBF," Molecular and Cellular Biology, vol. 30, no. 10, pp. 4952-4964, 2010.

[146] S. Y. Lee, J.-H. Park, S. Kim, E.-J. Park, Y. Yun, and J. Kwon, “A proteomics approach for the identification of nucleophosmin and heterogeneous nuclear ribonucleoprotein $\mathrm{C} 1 / \mathrm{C} 2$ as chromatin-binding proteins in response to DNA doublestrand breaks," Biochemical Journal, vol. 388, no. 1, pp. 7-15, 2005.

[147] A. Koike, H. Nishikawa, W. Wu et al., "Recruitment of phosphorylated NPM1 to sites of DNA damage through RNF8-dependent ubiquitin conjugates," Cancer Research, vol. 70, no. 17, pp. 6746-6756, 2010.

[148] B. Y.-M. Yung, H. Busch, and P.-K. Chan, "Translocation of nucleolar phosphoprotein B23 ( $37 \mathrm{kDa}$ pI 5.1) induced by selective inhibitors of ribosome synthesis," Biochimica et Biophysica Acta, vol. 826, no. 4, pp. 167-173, 1985.

[149] P. K. Chan, "Characterization and cellular localization of nucleophosmin/B23 in HeLa cells treated with selected cytotoxic agents (studies of B23-translocation mechanism)," Experimental Cell Research, vol. 203, no. 1, pp. 174-181, 1992.

[150] M. H. Wu, J. H. Chang, C. C. Chou, and B. Y. M. Yung, "Involvement of nucleophosmin/B23 in the response of HeLa cells to UV irradiation," International Journal of Cancer, vol. 97, no. 3, pp. 297-305, 2002.

[151] C. Yang, D. A. Maiguel, and F. Carrier, "Identification of nucleolin and nucleophosmin as genotoxic stress-responsive RNA-binding proteins," Nucleic Acids Research, vol. 30, no. 10, pp. 2251-2260, 2002.

[152] M. H. Wu, J. H. Chang, and B. Y. M. Yung, "Resistance to UVinduced cell-killing in nucleophosmin/B23 over-expressed NIH 3T3 fibroblasts: enhancement of DNA repair and upregulation of PCNA in association with nucleophosmin/B23 over-expression," Carcinogenesis, vol. 23, no. 1, pp. 93-100, 2002.
[153] J. Linger and J. K. Tyler, "The yeast histone chaperone chromatin assembly factor 1 protects against double-strand DNA-damaging agents," Genetics, vol. 171, no. 4, pp. 15131522, 2005.

[154] A. Rousselet, "Inhibiting Crm1 causes the formation of excess acentriolar spindle poles containing NuMA and B23, but does not affect centrosome numbers," Biology of the Cell, vol. 101, no. 12, pp. 679-693, 2009.

[155] K. Shinmura, P. Tarapore, Y. Tokuyama, K. R. George, and K. Fukasawa, "Characterization of centrosomal association of nucleophosmin/B23 linked to Crm1 activity," FEBS Letters, vol. 579, no. 29, pp. 6621-6634, 2005.

[156] S. N. Brady, L. B. Maggi, C. L. Winkeler et al., "Nucleophosmin protein expression level, but not threonine 198 phosphorylation, is essential in growth and proliferation," Oncogene, vol. 28, no. 36, pp. 3209-3220, 2009.

[157] D. R. Foltz, L. E. Jansen, B. E. Black, A. O. Bailey, J. R. Yates III, and D. W. Cleveland, "The human CENP-A centromeric nucleosome-associated complex," Nature Cell Biology, vol. 8, no. 5, pp. 458-469, 2006.

[158] E. M. Dunleavy, D. Roche, H. Tagami et al., "HJURP is a cell-cycle-dependent maintenance and deposition factor of CENP-A at centromeres," Cell, vol. 137, no. 3, pp. 485-497, 2009.

[159] D. R. Foltz, L. E. T. Jansen, A. O. Bailey et al., "Centromerespecific assembly of CENP-A nucleosomes is mediated by HJURP," Cell, vol. 137, no. 3, pp. 472-484, 2009.

[160] M. A. Amin, S. Matsunaga, S. Uchiyama, and K. Fukui, "Depletion of nucleophosmin leads to distortion of nucleolar and nuclear structures in HeLa cells," Biochemical Journal, vol. 415, no. 3, pp. 345-351, 2008.

[161] I. Ugrinova, K. Monier, C. Ivaldi et al., "Inactivation of nucleolin leads to nucleolar disruption, cell cycle arrest and defects in centrosome duplication," BMC Molecular Biology, vol. 8, article 66, 2007.

[162] D. Angelov, V. A. Bondarenko, S. Almagro et al., "Nucleolin is a histone chaperone with FACT-like activity and assists remodeling of nucleosomes," EMBO Journal, vol. 25, no. 8, pp. 1669-1679, 2006.

[163] D. Ruggero and P. P. Pandolfi, "Does the ribosome translate cancer?" Nature Reviews Cancer, vol. 3, no. 3, pp. 179-192, 2003.

[164] N. Feuerstein, P. K. Chan, and J. J. Mond, "Identification of numatrin, the nuclear matrix protein associated with induction of mitogenesis, as the nucleolar protein B23. Implication for the role of the nucleolus in early transduction of mitogenic signals," Journal of Biological Chemistry, vol. 263, no. 22, pp. 10608-10612, 1988.

[165] N. Feuerstein and J. J. Mond, “"Numatrin," a nuclear matrix protein associated with induction of proliferation in B lymphocytes," Journal of Biological Chemistry, vol. 262, no. 23, pp. 11389-11397, 1987.

[166] N. Feuerstein, S. Spiegel, and J. J. Mond, “The nuclear matrix protein, numatrin (B23), is associated with growth factorinduced mitogenesis in Swiss 3T3 fibroblasts and with T lymphocyte proliferation stimulated by lectins and anti-T cell antigen receptor antibody," Journal of Cell Biology, vol. 107, no. 5, pp. 1629-1642, 1988.

[167] A. Pianta, C. Puppin, A. Franzoni et al., "Nucleophosmin is overexpressed in thyroid tumors," Biochemical and Biophysical Research Communications, vol. 397, no. 3, pp. 499-504, 2010.

[168] M. Gimenez, V. C. de Oliveira Souza, C. Izumi et al., "Proteomic analysis of low- to high-grade astrocytomas 
reveals an alteration of the expression level of raf kinase inhibitor protein and nucleophosmin," Proteomics, vol. 10, no. 15, pp. 2812-2821, 2010.

[169] J.-P. Yun, J. Miao, G. G. Chen et al., "Increased expression of nucleophosmin/B23 in hepatocellular carcinoma and correlation with clinicopathological parameters," British Journal of Cancer, vol. 96, no. 3, pp. 477-484, 2007.

[170] K. I. Zeller, T. J. Haggerty, J. F. Barrett, Q. Guo, D. R. Wonsey, and C. V. Dang, "Characterization of nucleophosmin (B23) as a Myc target by scanning chromatin immunoprecipitation," Journal of Biological Chemistry, vol. 276, no. 51, pp. 48285-48291, 2001.

[171] T. Naoe, T. Suzuki, H. Kiyoi, and T. Urano, "Nucleophosmin: a versatile molecule associated with hematological malignancies," Cancer Science, vol. 97, no. 10, pp. 963-969, 2006.

[172] D. Bischof, K. Pulford, D. Y. Mason, and S. W. Morris, "Role of the nucleophosmin (NPM) portion of the non-Hodgkin's lymphoma-associated NPM-anaplastic lymphoma kinase fusion protein in oncogenesis," Molecular and Cellular Biology, vol. 17, no. 4, pp. 2312-2325, 1997.

[173] S. W. Morris, M. N. Kirstein, M. B. Valentine et al., "Fusion of a kinase gene, ALK, to a nucleolar protein gene, NPM, in non-Hodgkin's lymphoma," Science, vol. 263, no. 5151, pp. 1281-1284, 1994.

[174] B. Falini, C. Mecucci, E. Tiacci et al., "Cytoplasmic nucleophosmin in acute myelogenous leukemia with a normal karyotype," New England Journal of Medicine, vol. 352, no. 3, pp. 254-266, 2005.

[175] B. Falini, N. Bolli, A. Liso et al., "Altered nucleophosmin transport in acute myeloid leukaemia with mutated NPM1: molecular basis and clinical implications," Leukemia, vol. 23, no. 10, pp. 1731-1743, 2009.

[176] P. Sportoletti, S. Grisendi, S. M. Majid et al., "Npm1 is a haploinsufficient suppressor of myeloid and lymphoid malignancies in the mouse," Blood, vol. 111, no. 7, pp. 38593862, 2008.

[177] N. E. Sharpless, "INK4a/ARF: a multifunctional tumor suppressor locus," Mutation Research, vol. 576, no. 1-2, pp. 22-38, 2005.

[178] E. Colombo, P. Martinelli, R. Zamponi et al., "Delocalization and destabilization of the Arf tumor suppressor by the leukemia-associated NPM mutant," Cancer Research, vol. 66, no. 6, pp. 3044-3050, 2006.

[179] W. den Besten, M.-L. Kuo, R. T. Williams, and C. J. Sherr, "Myeloid leukemia-associated nucleophosmin mutants perturb p53-dependent and independent activities of the Arf tumor suppressor protein," Cell Cycle, vol. 4, no. 11, pp. 1591-1596, 2005.

[180] M. Welcker, A. Orian, J. A. Grim, R. N. Eisenman, and B. E. Clurman, "A nucleolar isoform of the Fbw7 ubiquitin ligase regulates c-Myc and cell size," Current Biology, vol. 14, no. 20, pp. 1852-1857, 2004.

[181] Z. Li and S. R. Hann, "The Myc-nucleophosmin-ARF network: a complex web unveiled," Cell Cycle, vol. 8, no. 17, pp. 2703-2707, 2009.

[182] M. S. Lindström, C. Deisenroth, and Y. Zhang, "Putting a finger on growth surveillance: insight into MDM2 zinc finger-ribosomal protein interactions," Cell Cycle, vol. 6, no. 4, pp. 434-437, 2007.

[183] A. Narla and B. L. Ebert, "Ribosomopathies: human disorders of ribosome dysfunction," Blood, vol. 115, no. 16, pp. 3196-3205, 2010.
[184] B. Falini, N. Bolli, J. Shan et al., "Both carboxy-terminus NES motif and mutated tryptophan(s) are crucial for aberrant nuclear export of nucleophosmin leukemic mutants in NPMc+ AML," Blood, vol. 107, no. 11, pp. 4514-4523, 2006.

[185] H. J. Chan, J. J. Weng, and B. Y. M. Yung, "Nucleophosmin/B23-binding peptide inhibits tumor growth and upregulates transcriptional activity of p53," Biochemical and Biophysical Research Communications, vol. 333, no. 2, pp. 396-403, 2005.

[186] Y. Perera, H. G. Farina, J. Gil et al., “Anticancer peptide CIGB300 binds to nucleophosmin/B23, impairs its CK2-mediated phosphorylation, and leads to apoptosis through its nucleolar disassembly activity," Molecular Cancer Therapeutics, vol. 8, no. 5, pp. 1189-1196, 2009.

[187] J. E. Wulff, R. Siegrist, and A. G. Myers, "The natural product avrainvillamide binds to the oncoprotein nucleophosmin," Journal of the American Chemical Society, vol. 129, no. 46, pp. 14444-14451, 2007.

[188] W. Qi, K. Shakalya, A. Stejskal et al., "NSC348884, a nucleophosmin inhibitor disrupts oligomer formation and induces apoptosis in human cancer cells," Oncogene, vol. 27, no. 30, pp. 4210-4220, 2008.

[189] Y. Jian, Z. Gao, J. Sun et al., "RNA aptamers interfering with nucleophosmin oligomerization induce apoptosis of cancer cells," Oncogene, vol. 28, no. 47, pp. 4201-4211, 2009.

[190] Y. Qing, G. Yingmao, B. Lujun, and L. shaoling, "Role of Npm1 in proliferation, apoptosis and differentiation of neural stem cells," Journal of the Neurological Sciences, vol. 266, no. 1-2, pp. 131-137, 2008.

[191] J. Li, X. Zhang, D. P. Sejas, and Q. Pang, "Negative regulation of $\mathrm{p} 53$ by nucleophosmin antagonizes stress-induced apoptosis in human normal and malignant hematopoietic cells," Leukemia Research, vol. 29, no. 12, pp. 1415-1423, 2005.

[192] V. Palaniswamy, K. C. M. Moraes, C. J. Wilusz, and J. Wilusz, "Nucleophosmin is selectively deposited on mRNA during polyadenylation," Nature Structural and Molecular Biology, vol. 13, no. 5, pp. 429-435, 2006.

[193] P. Tarapore, K. Shinmura, H. Suzuki et al., "Thr199 phosphorylation targets nucleophosmin to nuclear speckles and represses pre-mRNA processing," FEBS Letters, vol. 580, no. 2, pp. 399-409, 2006.

[194] Y. Nawa, K.-I. Kawahara, S. Tancharoen et al., "Nucleophosmin may act as an alarmin: implications for severe sepsis," Journal of Leukocyte Biology, vol. 86, no. 3, pp. 645-653, 2009.

[195] D. K. Crockett, Z. Lin, K. S. J. Elenitoba-Johnson, and M. S. Lim, "Identification of NPM-ALK interacting proteins by tandem mass spectrometry," Oncogene, vol. 23, no. 15, pp. 2617-2629, 2004.

[196] H. Tamada, N. van Thuan, P. Reed et al., "Chromatin decondensation and nuclear reprogramming by nucleoplasmin," Molecular and Cellular Biology, vol. 26, no. 4, pp. 1259-1271, 2006.

[197] Z. Lu, C. Zhang, and Z. Zhai, "Nucleoplasmin regulates chromatin condensation during apoptosis," Proceedings of the National Academy of Sciences of the United States of America, vol. 102, no. 8, pp. 2778-2783, 2005. 

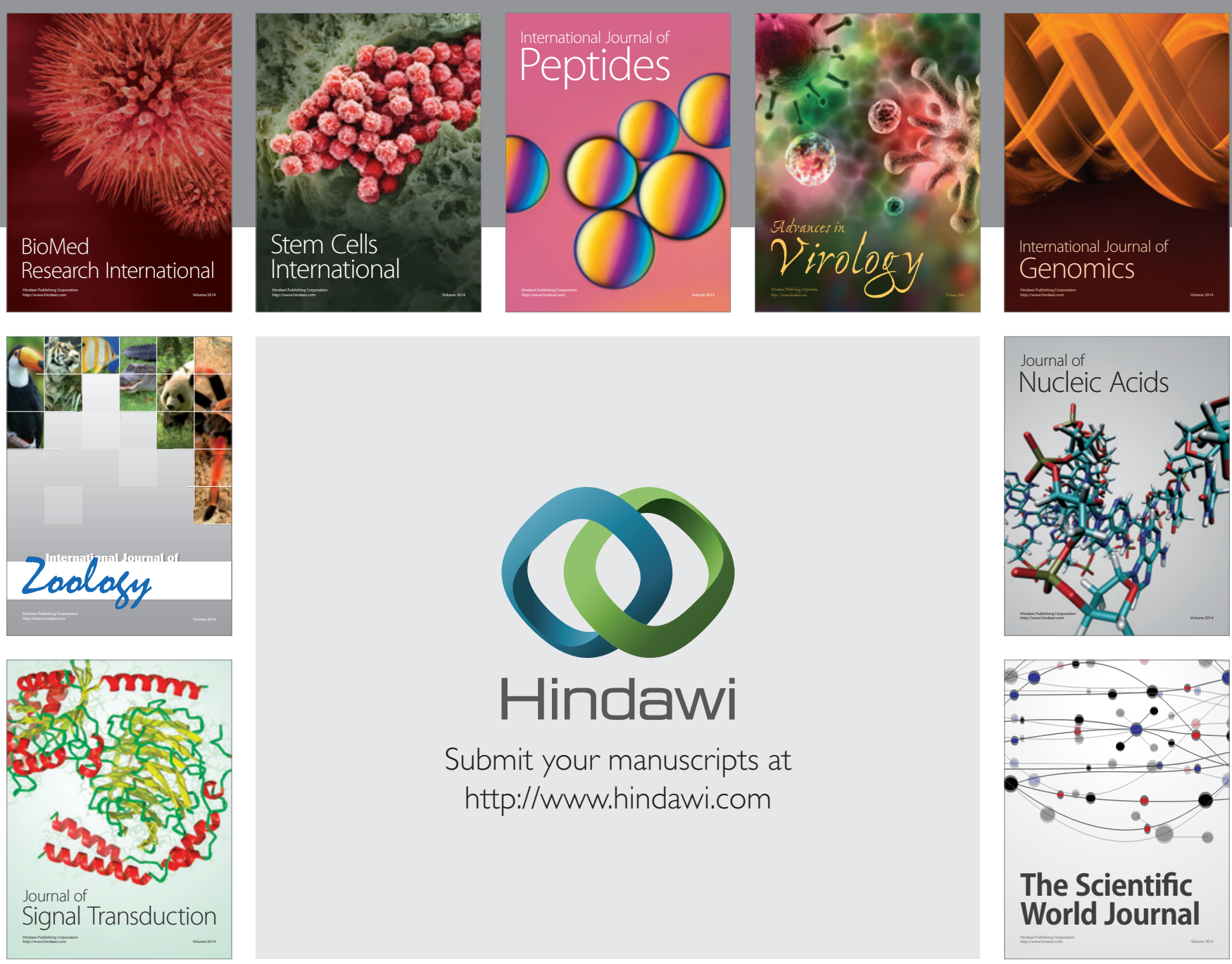

Submit your manuscripts at

http://www.hindawi.com
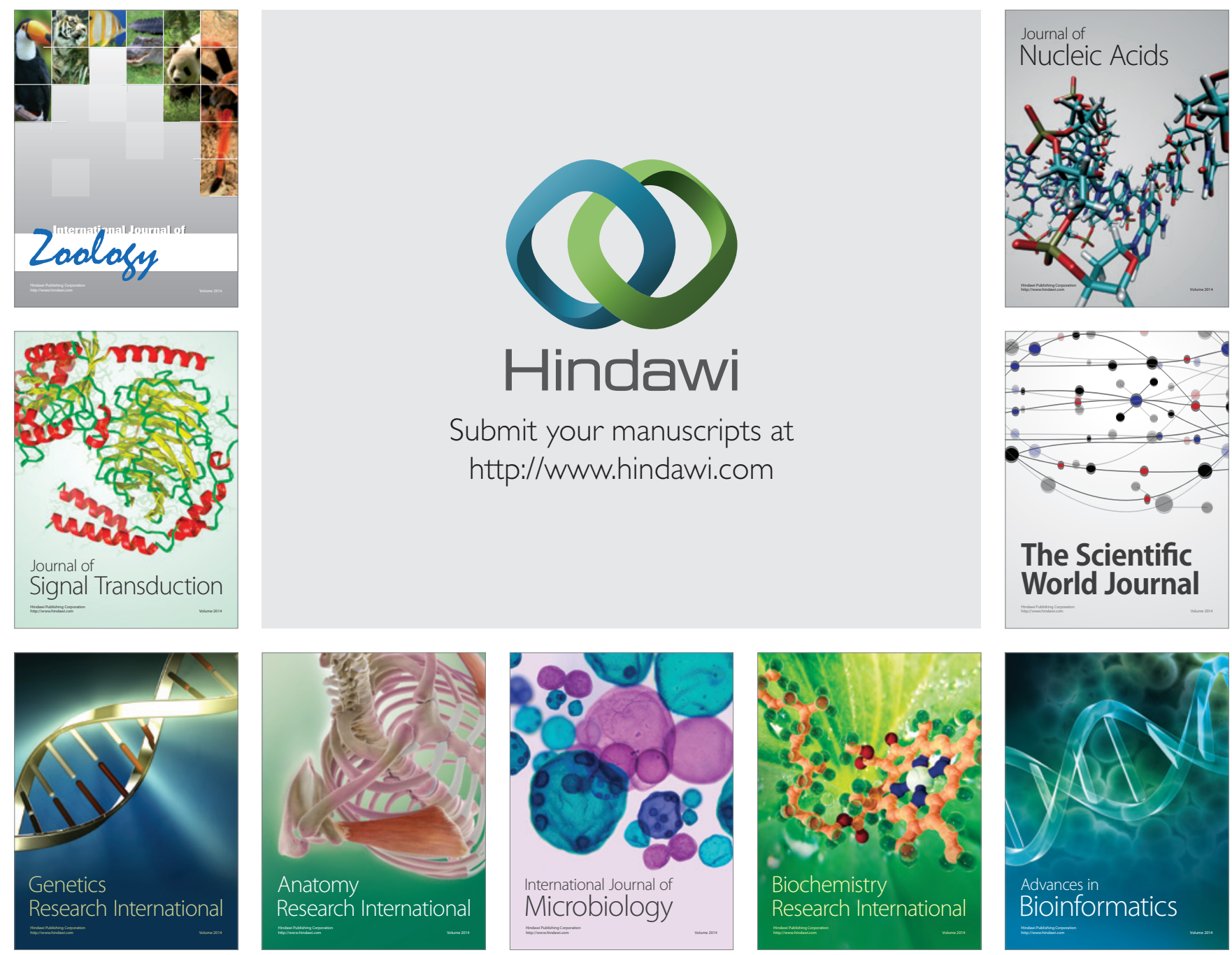

The Scientific World Journal
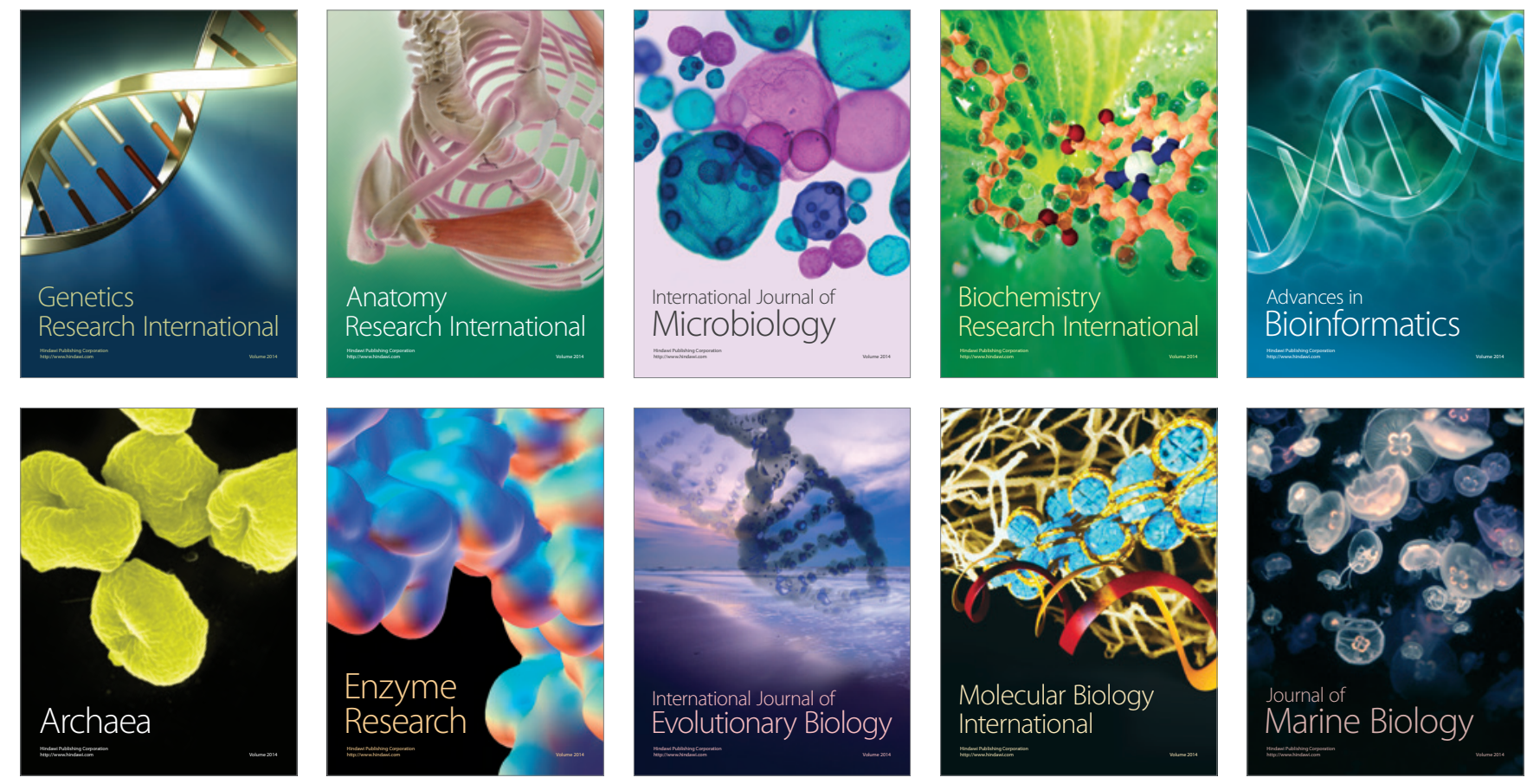